\title{
Additional Investigations of Ice Shape Sensitivity to Parameter Variations
}

Dean R. Miller and Mark G. Potapczuk

Glenn Research Center, Cleveland, Ohio

Tammy J. Langhals

QSS Group, Inc., Cleveland, Ohio 


\section{NASA STI Program . . . in Profile}

Since its founding, NASA has been dedicated to the advancement of aeronautics and space science. The NASA Scientific and Technical Information (STI) program plays a key part in helping NASA maintain this important role.

The NASA STI Program operates under the auspices of the Agency Chief Information Officer. It collects, organizes, provides for archiving, and disseminates NASA's STI. The NASA STI program provides access to the NASA Aeronautics and Space Database and its public interface, the NASA Technical Reports Server, thus providing one of the largest collections of aeronautical and space science STI in the world. Results are published in both non-NASA channels and by NASA in the NASA STI Report Series, which includes the following report types:

- TECHNICAL PUBLICATION. Reports of completed research or a major significant phase of research that present the results of NASA programs and include extensive data or theoretical analysis. Includes compilations of significant scientific and technical data and information deemed to be of continuing reference value. NASA counterpart of peer-reviewed formal professional papers but has less stringent limitations on manuscript length and extent of graphic presentations.

- TECHNICAL MEMORANDUM. Scientific and technical findings that are preliminary or of specialized interest, e.g., quick release reports, working papers, and bibliographies that contain minimal annotation. Does not contain extensive analysis.

- CONTRACTOR REPORT. Scientific and technical findings by NASA-sponsored contractors and grantees.
- CONFERENCE PUBLICATION. Collected papers from scientific and technical conferences, symposia, seminars, or other meetings sponsored or cosponsored by NASA.

- SPECIAL PUBLICATION. Scientific, technical, or historical information from NASA programs, projects, and missions, often concerned with subjects having substantial public interest.

- TECHNICAL TRANSLATION. Englishlanguage translations of foreign scientific and technical material pertinent to NASA's mission.

Specialized services also include creating custom thesauri, building customized databases, organizing and publishing research results.

For more information about the NASA STI program, see the following:

- Access the NASA STI program home page at http://www.sti.nasa.gov

- E-mail your question via the Internet to help@sti.nasa.gov

- Fax your question to the NASA STI Help Desk at 301-621-0134

- Telephone the NASA STI Help Desk at 301-621-0390

- Write to:

NASA STI Help Desk

NASA Center for AeroSpace Information 7121 Standard Drive Hanover, MD 21076-1320 


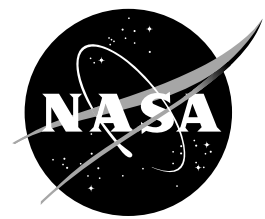

\section{Additional Investigations of Ice Shape Sensitivity to Parameter Variations}

Dean R. Miller and Mark G. Potapczuk

Glenn Research Center, Cleveland, Ohio

Tammy J. Langhals

QSS Group, Inc., Cleveland, Ohio

Prepared for the

44th Aerospace Sciences Meeting and Exhibit

sponsored by the American Institute of Aeronautics and Astronautics

Reno, Nevada, January 9-12, 2006

National Aeronautics and

Space Administration

Glenn Research Center

Cleveland, Ohio 44135 


\section{Acknowledgments}

The authors would like to acknowledge the contributions of Robert Ide and John Oldenburg of NASA Glenn Research Center for their insight in the design of this experiment, and for their help in selecting the conditions used for this study. The authors would also like to recognize the contributions of the NASA Icing Research Tunnel staff for their technical support and operation of the icing tunnel in support of this investigation.

Level of Review: This material has been technically reviewed by technical management.

Available from

NASA Center for Aerospace Information 7121 Standard Drive

Hanover, MD 21076-1320
National Technical Information Service 5285 Port Royal Road Springfield, VA 22161

Available electronically at http://gltrs.grc.nasa.gov 


\title{
Additional Investigations of Ice Shape Sensitivity to Parameter Variations
}

\author{
Dean R. Miller and Mark G. Potapczuk \\ National Aeronautics and Space Administration \\ Glenn Research Center \\ Cleveland, Ohio 44135 \\ Tammy J. Langhals \\ QSS Group, Inc. \\ Cleveland, Ohio 44135
}

\begin{abstract}
A second parameter sensitivity study was conducted at the NASA Glenn Research Center's Icing Research Tunnel (IRT) using a 36 in. chord $(0.91 \mathrm{~m})$ NACA-0012 airfoil. The objective of this work was to further investigate the feasibility of using ice shape feature changes to define requirements for the simulation and measurement of SLD and appendix C icing conditions. A previous study concluded that it was feasible to use changes in ice shape features (e.g., ice horn angle, ice horn thickness, and ice shape mass) to detect relatively small variations in icing spray condition parameters $(L W C, M V D$, and temperature). The subject of this current investigation extends the scope of this previous work, by also examining the effect of icing tunnel spray-bar parameter variations (water pressure, air pressure) on ice shape feature changes. The approach was to vary spray-bar water pressure and air pressure, and then evaluate the effects of these parameter changes on the resulting ice shapes. This paper will provide a description of the experimental method, present selected experimental results, and conclude with an evaluation of these results.
\end{abstract}

\section{Nomenclature}

$\begin{array}{ll}A O A & \text { angle of attack } \\ \text { IRT } & \text { Icing Research Tunnel } \\ L W C & \text { liquid water content } \\ M V D & \text { median volume diameter } \\ \text { SLD } & \text { super-cooled large droplets } \\ T_{t o t} & \text { total temperature } \\ T_{s} & \text { static temperature } \\ V & \text { airspeed } \\ \eta_{0} & \text { stagnation line freezing fraction } \\ P_{\text {air }} & \text { spraybar air pressure parameter } \\ \Delta P & \text { spraybar water pressure parameter }\end{array}$

\section{Introduction}

How good does it have to be? That is a question which has been asked repeatedly of scientists and engineers developing new capabilities for simulation and measurement of SLD icing conditions. The recent emphasis by NASA and other international partners on extending the current capabilities of engineering tools (icing tunnels and tankers, ice accretion computer codes) to include Super-cooled Large Droplets (SLD) has once again focused renewed attention on this question. 
NASA and it's international partners developed an SLD Technology Roadmap to guide the development of SLD Engineering Tools to support certification in SLD icing conditions. This SLD Technology Roadmap identified the key technology elements and supporting research investments needed to develop SLD engineering tools (ref. 1). The SLD Technology Roadmap was later translated into a project plan having a schedule and Work Breakdown Structure (WBS) (ref. 2).

During the initial stages of developing these technical plans, it was recognized that requirements were needed to define "how good" the SLD simulation capabilities needed to be. Therefore, a specific task was incorporated into the SLD Engineering Tool Development Project Plan to address this need (Task 1.1) (ref. 2). The definition of requirements was intended to provide a "target" for SLD simulation in quantified terms. This served the dual purpose of providing guidance about: (1) what essential features or characteristics need to be simulated and (2) how accurately these characteristics need to be simulated. It was anticipated that these requirements would be developed by means of sensitivity studies, either experimental or computational.

Two important areas of the project plan, where the definition of requirements would be very beneficial, are: (1) updating ice prediction codes to include SLD icing effects and (2) development and assessment of icing cloud instrumentation to measure SLD icing conditions. Though work has been proceeding in these areas, it would be desirable to define limits for "how good" the SLD ice prediction capability and SLD icing condition measurement need to be.

The authors conducted an initial sensitivity study to investigate the feasibility of using changes in ice shape features as a potential method for defining requirements (ref. 3). This idea to study ice shape feature changes was based on an assumption that ice shape features (ice horn thickness and angle) could serve as a central link relating changes in simulation parameters (e.g., $L W C, M V D$, and temperature) to aerodynamic performance effects resulting from those feature changes. If this link could be established, then acceptable changes in aerodynamic performance could potentially be used to define acceptable changes in ice shape features, and in turn the ice shape feature variations could be used to define requirements for the acceptable limit of variation in icing simulation parameters.

The objective of the initial sensitivity study was to determine if variations in $L W C, M V D$, and temperature would result in perceivable changes in ice shape features. Since it was not known a priori if ice shape feature changes would be discernible, or what level of parameter variation was required to result in a perceivable change, values were chosen based on engineering experience. The following values for parameter variation were chosen based on a belief that they provided a significant enough variation so as to produce a discernible change in ice shape features: $\left( \pm 0.1 \mathrm{~g} / \mathrm{m}^{3}\right.$ about a nominal $L W C$ of $\left.0.6 \mathrm{~g} / \mathrm{m}^{3}\right)$, $( \pm 50 \mu \mathrm{m}$ about a nominal $M V D$ of $80 \mu \mathrm{m})$, and $\left( \pm 3{ }^{\circ} \mathrm{F}\right.$ about a nominal temperature defined by the freezing fraction. Changes in ice shape features with respect to a nominal condition were documented for these parameter variations for a freezing fraction of 0.3 and 0.7 .

The results from this investigation confirmed that variations in $L W C, M V D$, and temperature did indeed yield distinguishable changes in ice shape features. The effect of parameter variations on ice shape features were qualitatively assessed by comparing the variant condition ice shape with the nominal condition ice shape. Changes in ice horn angle and thickness were clearly visible, and these trends appeared to be consistent with what might be expected based on a knowledge of icing physics. LEWICE was also run for the nominal and variant conditions, and the predicted ice shapes were compared. A qualitative evaluation of these predicted ice shapes revealed similar trends in ice shape feature changes, as those observed in the actual ice shape tracings.

Ice shape features were also quantified. Changes in ice shape mass were quantified by removing ice from a selected portion of the NACA-0012 airfoil for each test condition, and subsequently weighing it.

An ice shape analysis program (THICK) developed by William Wright of QSS Group, Inc., at NASA Glenn Research Center was successfully used to compare ice shape tracings and quantify variation in upper and lower icing limit, upper and lower ice horn angle, upper and lower ice horn thickness, and area. Of these ice shape features, horn angles, horn thickness, and mass were believed to be the most reliable metrics on which to gauge changes. Icing limit and iced area measurements were deemed to have 
significant variability, due to uncertainties inherent in the ice tracing process, and thus were not used as metrics to evaluate ice feature changes.

A significant conclusion drawn from this initial study was that smaller parameter variations (than those used in this initial study) might produce discernible changes in ice shape features. These variations were to thought be on the order of $0.1 \mathrm{~g} / \mathrm{m}^{3}$ or less for $L W C$, on the order of $10 \mu \mathrm{m}$ for $M V D$, and on the order of $1.0^{\circ} \mathrm{F}$ or less for temperature. Results also suggested that changes in ice horn angle and mass might be sensitive enough to evaluate potentially smaller parameter variations, but the study was not conclusive enough to establish the minimum parameter variation that could practically be achieved.

Therefore, it was decided to conduct another ice shape sensitivity test to look at smaller variations in icing parameters and assess their impact on ice shape features. To do this a slightly different approach was taken from the first investigation. This parameter sensitivity study was again conducted at the NASA Glenn Research Center's Icing Research Tunnel (IRT) using a 36 in. chord (0.91 m) NACA-0012 airfoil. Spraybar air pressure and water pressure were varied with respect to a nominal value, effectively changing $M V D$ and $L W C$ with respect to that nominal condition. Resultant changes in (1) mass, (2) upper horn angle, (3) lower horn angle, (4) upper horn thickness, and (5) lower horn thickness were assessed.

This paper will first describe the experimental approach, test configuration, and test conditions associated with this experimental investigation. Then the analysis methodology will be presented, followed by a qualitative and quantitative analysis of changes in the five ice shape features noted above. The report will conclude with an assessment of the experimental and analytical methods, address the significance of the results, and provide recommendations for future research.

\section{Experimental Methodology}

\section{A. Approach}

The objective of this experimental sensitivity study was to conduct a more detailed investigation of ice shape feature changes resulting from variations in $L W C$ and $M V D$. As with the previous study the overall motivation for the research was to use this knowledge for the purpose of developing requirements for improvements to SLD ice prediction codes, and the instrumentation used to measure SLD icing conditions.

The basic plan was to use an icing wind tunnel to vary spraybar air and water pressure (which effectively vary $L W C$ and $M V D$ ), about a nominal condition, document changes in the resultant ice shapes, and in some manner use these changes as a metric for developing accuracy estimates. Since it was desired to evaluate ice shape feature changes, on a finer resolution scale than the previous study, more test conditions would be required. Ultimately, it was desired to identify the minimum change in a parameter (threshold) which produces an observable change in the resulting ice shape. This "threshold" value could then be used to develop an estimate of the required accuracy for that parameter.

For this sensitivity test spraybar air and water pressure were specified as parameters rather than $L W C$ and $M V D$ (as in the previous test). It was believed there were two important benefits to this approach: (1) we could precisely specify an air pressure and water pressure point for which spraybar drop size and $L W C$ calibration data were acquired (thus minimizing potential uncertainties in the value of the associated $L W C$ and $M V D$ ) and (2) the existence of a drop size distribution could facilitate later more detailed analyses of the ice feature changes using the unique attributes of an actual distribution versus an $M V D$.

One complication to this approach was that ice feature changes would now be a function of a combined $L W C$ and $M V D$ change, since changes in water pressure affected both $L W C$ and $M V D$. Thus it would not be possible to specifically isolate effects due to just $L W C$ changes or $M V D$ changes as in the previous test. To address this issue, spray conditions were selected in such a way so as to create a grid of variant condition test points surrounding the nominal condition. This facilitated the use of two-

dimensional contour plots to better illustrate or map ice shape feature variation (e.g., mass, ice horn angle, and ice horn thickness), due to a combined effect in a highly resolved way. 


\section{B. Test Configuration}

The sensitivity study was conducted in the NASA Glenn Icing Research Tunnel (IRT) which is a closed-loop refrigerated wind tunnel. The test section is $6 \mathrm{ft}(1.83 \mathrm{~m})$ high and $9 \mathrm{ft}(2.74 \mathrm{~m})$ wide, and contains a turntable assembly which allows for model angle-of-attack changes. A $5000 \mathrm{hp}$ fan provides airspeeds up to $390 \mathrm{mph}$ (empty test section). The refrigeration heat exchanger can control air temperature from $40^{\circ} \mathrm{F}\left(4.4^{\circ} \mathrm{C}\right)$ to $-20^{\circ} \mathrm{F}\left(-28.9^{\circ} \mathrm{C}\right)$. The water spray system has been calibrated for simulating icing clouds with droplet $M V D$ of 10 to $216 \mu \mathrm{m}$, and Liquid Water Content ( $L W C$ ) of 0.2 to $3.4 \mathrm{~g} / \mathrm{m}^{3}$.

The test article was a $3 \mathrm{ft}(0.914 \mathrm{~m})$ chord NACA-0012 airfoil having a $6 \mathrm{ft}(1.83 \mathrm{~m})$ span. It was mounted vertically in the test section, and was fixed at a $2.5^{\circ}$ angle-of attack for all the conditions tested. A heater mat was installed on the model to assist in removing the ice accretion and making mass measurements.

The ice removal area extended approximately $9 \mathrm{in}$. $(0.23 \mathrm{~m})$ above and below the vertical centerline of the tunnel (which was at $3 \mathrm{ft}(0.914 \mathrm{~m})$ from the floor), and wrapped around the airfoil 6 in. $(0.089 \mathrm{~m})$ on the upper surface of the airfoil, and 9 in. $(0.216 \mathrm{~m})$ on the lower surface.

This test was conducted in three segments (August 2004, February 2005, and September 2005). During the time period between the first and second entries, the heater mat was removed from the airfoil. Another heater mat was installed on the airfoil and used for the second and third test entries. As a result, the vertical dimension of the ice removal areas differed slightly between the 2004 test entry and the 2005 test entries. For the 2004 entry it was 17.5 in. $(0.45 \mathrm{~m})$, and for the 2005 test entries it was $18.5 \mathrm{in}$. $(0.47 \mathrm{~m})$.

The $2.5^{\circ} A O A$ was chosen to provide some difference between the upper and lower surface ice shapes of this symmetrical airfoil. A pressure belt was initially installed on the airfoil and used to determine the $0^{\circ} A O A$, which corresponded to an IRT turntable setting of $-0.8^{\circ}$. The turntable was then set to $1.7^{\circ}$ to achieve a $2.5^{\circ} \mathrm{AOA}$. The test article is shown installed in the IRT test section in figure 1.

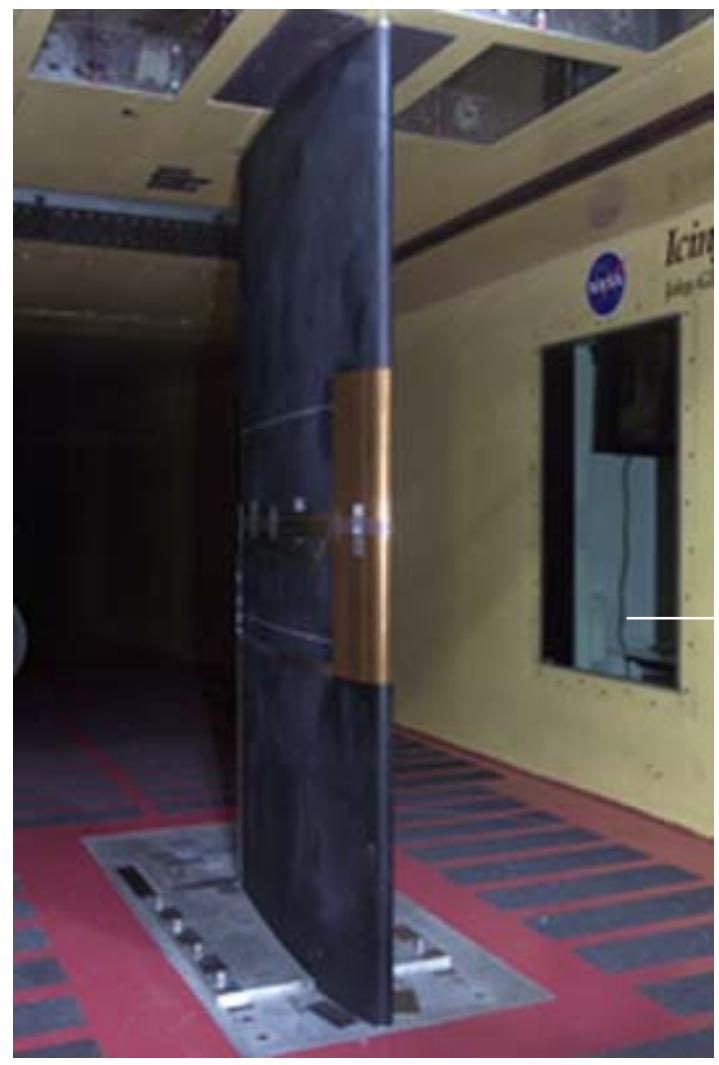

Figure 1.-NACA-0012 airfoil installed in the test section of the NASA IRT. 


\section{Test Conditions}

The spraybar and tunnel test conditions utilized in this sensitivity study are tabulated in table 1 . All spray bar pressures correspond to Mod-1 nozzle settings. The spraybar pressures and corresponding $M V D$ and $L W C$ are listed, along with the airspeed, $A O A$, and spray time. There were many more test conditions for this sensitivity study, than the previous study because of the desire to look at smaller parameter variations in this study. Thus, one can contrast the 29 conditions associated with this test versus the 10 test conditions for the previous sensitivity study.

TABLE 1.-ICING SENSITIVITY STUDY TEST CONDITIONS

\begin{tabular}{|c|c|c|c|c|c|c|c|c|}
\hline Condition & Pair (psi) & $\Delta \mathrm{P} \quad(\mathrm{psi})$ & $\begin{array}{l}\text { MVD } \\
(\mu \mathrm{m})\end{array}$ & $\begin{array}{c}\text { LWC } \\
(\mathrm{g} / \mathrm{m} 3)\end{array}$ & V (knots) & $\begin{array}{c}\text { AOA } \\
\text { (degrees) }\end{array}$ & \begin{tabular}{|c} 
SprayTime \\
$(\mathrm{min})$
\end{tabular} & Comments \\
\hline 1 & 15 & 50 & 28.2 & 0.527 & 200 & 2.5 & 15 & \\
\hline 2 & 15 & 60 & 31.8 & 0.578 & $"$ & $"$ & $"$ & \\
\hline 3 & 15 & 70 & 35.5 & 0.625 & $"$ & $"$ & $"$ & \\
\hline 4 & 15 & 80 & 39.4 & 0.669 & $"$ & $"$ & $"$ & \\
\hline 5 & 20 & 70 & 25.1 & 0.628 & $"$ & $"$ & $"$ & \\
\hline 6 & 20 & 80 & 27.5 & 0.672 & $"$ & $"$ & $"$ & \\
\hline 7 & 20 & 90 & 29.9 & 0.714 & $"$ & $"$ & $"$ & \\
\hline 8 & 20 & 100 & 32.4 & 0.753 & $"$ & $"$ & $"$ & \\
\hline 9 & 20 & 110 & 35 & 0.79 & $"$ & $"$ & $"$ & \\
\hline 10 & 25 & 70 & 20.2 & 0.629 & $"$ & $"$ & $"$ & \\
\hline 11 & 25 & 80 & 21.8 & 0.674 & $"$ & $"$ & $"$ & \\
\hline 12 & 25 & 90 & 23.5 & 0.715 & $"$ & $"$ & $"$ & \\
\hline 13 & 25 & 100 & 25.2 & 0.754 & $"$ & $"$ & $"$ & \\
\hline 14 & 25 & 110 & 26.9 & 0.791 & $"$ & $"$ & $"$ & \\
\hline 15 & 25 & 120 & 28.7 & 0.827 & $"$ & $"$ & $"$ & $\begin{array}{l}\text { Nominal } \\
\text { Condition }\end{array}$ \\
\hline 16 & 25 & 130 & 30.6 & 0.861 & $"$ & $"$ & $"$ & \\
\hline 17 & 25 & 140 & 32.6 & 0.893 & $"$ & $"$ & $"$ & \\
\hline 18 & 25 & 150 & 34.6 & 0.925 & $"$ & $"$ & $"$ & \\
\hline 19 & 25 & 160 & 36.7 & 0.955 & $"$ & $"$ & $"$ & \\
\hline 20 & 25 & 170 & 38.9 & 0.985 & $"$ & $"$ & $"$ & \\
\hline 21 & 30 & 100 & 21.3 & 0.753 & $"$ & $"$ & $"$ & \\
\hline 22 & 30 & 120 & 23.9 & 0.825 & $"$ & $"$ & " & \\
\hline 23 & 30 & 140 & 26.7 & 0.892 & " & " & " & \\
\hline 24 & 30 & 160 & 29.6 & 0.954 & $"$ & $"$ & $"$ & \\
\hline 25 & 30 & 180 & 32.9 & 1.012 & $"$ & " & " & \\
\hline 26 & 35 & 140 & 23.1 & 0.888 & $"$ & " & $"$ & \\
\hline 27 & 35 & 170 & 26.5 & 0.979 & " & " & $"$ & \\
\hline 28 & 40 & 150 & 21.6 & 0.912 & $"$ & $"$ & $"$ & \\
\hline 29 & 40 & 180 & 24.4 & 0.999 & $"$ & $"$ & $"$ & \\
\hline
\end{tabular}

Note: The conditions in this table were evaluated at two temperatures

1) $T_{\text {tot }}=23^{\circ} \mathrm{F}, T_{s}=13.5^{\circ} \mathrm{F}, \eta_{0}=0.39$

2) $T_{\text {tot }}=7.9^{\circ} \mathrm{F}, T_{s}=-1.6^{\circ} \mathrm{F}, \eta_{0}=0.75$

As in the previous study, the temperature effect was considered once again by testing at a relatively warm condition $\left(T_{t o t}=23^{\circ} \mathrm{F}, T_{s}=13.5^{\circ} \mathrm{F}\right)$ and relatively cold condition $\left(T_{t o t}=7.9^{\circ} \mathrm{F}, T_{s}=-1.6^{\circ} \mathrm{F}\right)$. This investigation did not hold freezing fraction, nor accumulation parameter steady. Instead, each variant condition was run, and it's resulting ice shape was traced, and then compared with the nominal condition ice tracing.

The nominal condition was defined by the following spraybar parameters $\left(P_{\text {air }}=25 \mathrm{psi}\right.$, $\Delta P=120 \mathrm{psi}$ ), corresponding to an $L W C$ of $0.827 \mathrm{~g} / \mathrm{m}^{3}$, and an $M V D$ of $28.7 \mu \mathrm{m}$. To help categorize warm and cold temperature ice tracings, the stagnation line freezing fraction was computed for the nominal condition at the warm temperature $\left(\eta_{0}=0.39\right)$ and cold temperature $\left(\eta_{0}=0.75\right)$. These nominal condition freezing fractions were then used to generally distinguish between ice shape tracing results obtained at the warm temperature versus those obtained at the cold temperature. Strictly speaking, however, if the freezing fraction had been computed for each variant case it would have differed from that computed for the nominal condition. 
The discrete grid of spray parameters $\left(P_{\text {air }}\right)$ and $(\Delta P)$ specified for this test are shown in figure 2 . They are shown overplotted versus the corresponding $L W C$ and $M V D$, to illustrate the fact that they effectively constitute a grid of points surrounding the nominal condition. It can be seen that when mapped in this way it should be possible to evaluate two-dimensional changes in ice shape features. Two red boxes are shown centered about the nominal condition to illustrate the limits of a \pm-10 or \pm-15 percent change in $L W C$ or $M V D$.

\section{Test Procedure}

The following test procedure was used for each of the test runs in this investigation.

a) Baseline and variation conditions were used to set tunnel operating values (i.e., tunnel velocity, air temperature, spray bar air, and water pressures)

b) Icing conditions were applied for the selected spray times

c) After the spray was concluded and the tunnel velocity was set to idle:

d) Photographs of the ice accretion were taken

e) An ice shape tracing was made at the mid-span location

f) The ice was cut at predetermined span-wise locations above and below mid-span

g) Heaters were turned on to de-bond the ice from the surface

h) Ice was removed and weighed

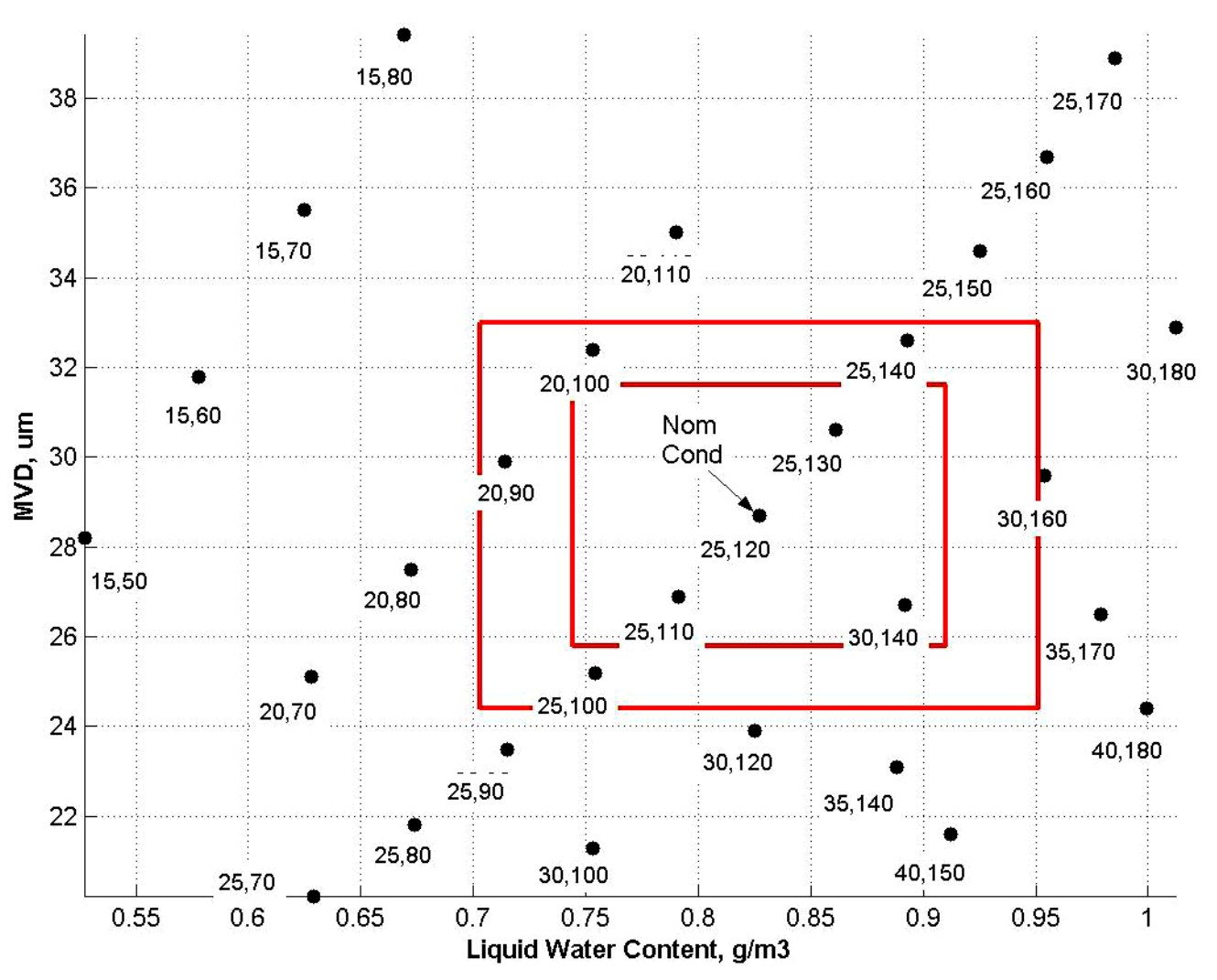

Figure 2.- Sensitivity spraybar test conditions mapped versus $M V D$ and $L W C$. 


\section{Analytical Methodology}

\section{A. Ice Shape Repeatability}

There is an inherent level of variation to ice shapes produced in an icing wind tunnel. Since this study intended to evaluate the effects of parameter changes on the resulting ice accretion, it was important to determine what level of change in ice shape features (general shape, horn location, mass, etc.) could be expected due to the normal run to run variations (repeatability) of the icing spray condition. This level of variation due to repeatability needs to be established to better assess the significance of ice shape feature changes.

\section{Qualitative Evaluation}

The "repeatability" of the nominal condition was established by analyzing the ice tracing features from multiple runs of the nominal condition. Figure 3 is a compilation of ice tracing comparisons from repeat runs of the nominal spray condition which had the following attributes: $L W C=0.827 \mathrm{~g} / \mathrm{m}^{3}$, $M V D=28.7 \mu \mathrm{m}, V=200 \mathrm{knots}, A O A=2.5^{\circ}$, and spray time $=15 \mathrm{~min}$. These ice tracings were obtained at two freezing fractions $\left(\eta_{0}=0.39\right.$ and 0.75$)$, and during test periods in 2004 and 2005.

Warm temperature ice tracings from 2004 and $2005\left(\eta_{0}=0.3\right)$ are displayed in figures 3(c) and (d). In general the ice tracings from 2004 looked very similar to those acquired in 2005. The 4 nominal condition ice tracings acquired in 2004 are shown in figure 3(c). The ice horn thickness and angles compare reasonably well for these runs, with the exception of run 15 (which displays a larger variation in horn

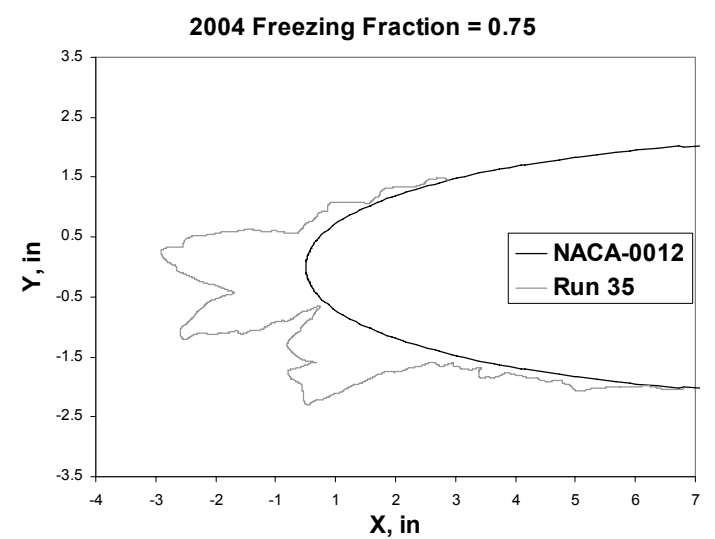

a) 2004 ice tracing, $T_{\text {tot }}=7.9^{\circ} \mathrm{F}, T_{\mathrm{s}}=-1.6^{\circ} \mathrm{F}, \eta_{0}=0.75$

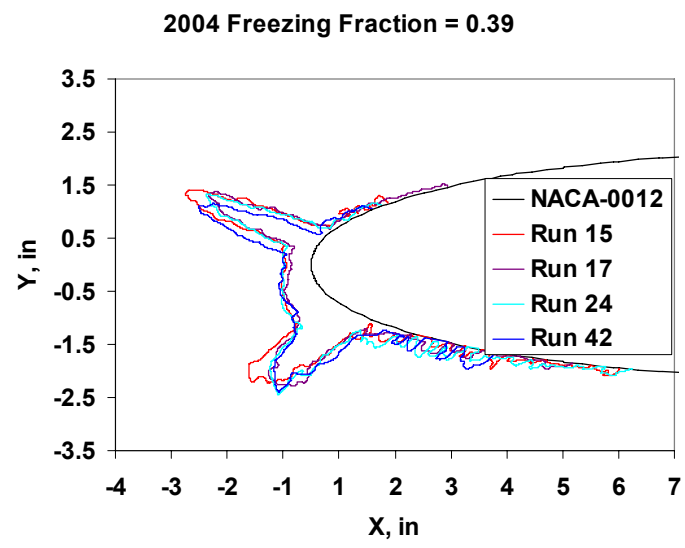

c) 2004 ice tracings, $T_{\text {tot }}=23^{\circ} \mathrm{F}, T_{s}=13.5^{\circ} \mathrm{F}, \eta_{0}=0.39$

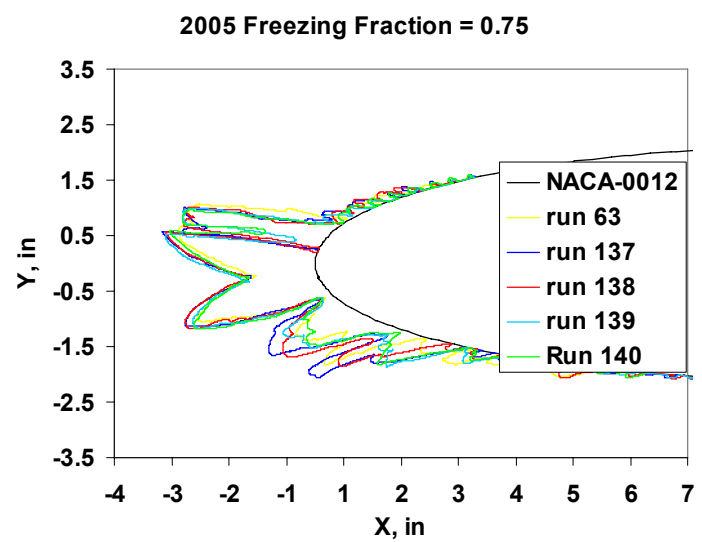

b) 2005 ice tracings, $T_{\text {tot }}=7.9^{\circ} \mathrm{F}, T_{\mathrm{s}}=-16^{\circ} \mathrm{F}, \eta_{0}=0.75$

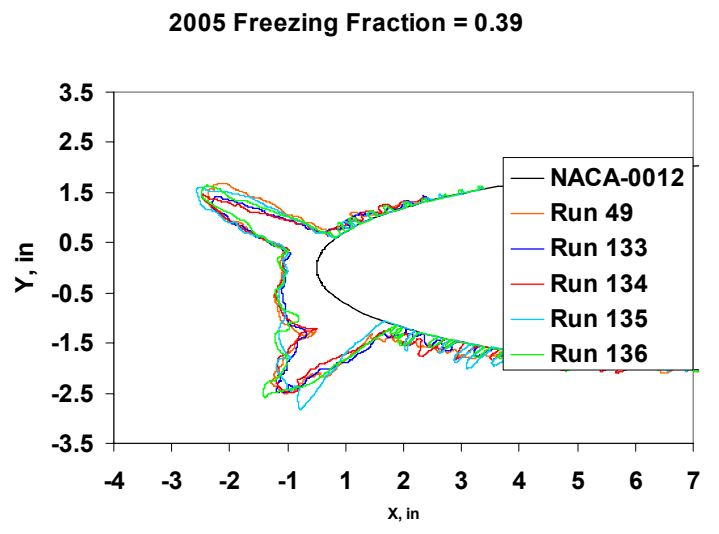

d) 2005 ice tracings, $T_{t o t}=23^{\circ} \mathrm{F}, T_{\mathrm{s}}=13.5^{\circ} \mathrm{F}, \eta_{0}=0.39$

Figure 3.-Nominal Condition ice shape repeatability, $P_{\text {air }}=25 \mathrm{psi}, \Delta P=120 \mathrm{psi}, L W C=0.827$, $M V D=28.7 \mu \mathrm{m}$. 
angle than the other runs). The 5 nominal condition ice tracings acquired at the warm condition in 2005 are plotted in figure 3(d). A comparison of ice horn thickness and horn angles for these 2005 runs also indicated reasonably good agreement among runs.

Ice tracings acquired at the cold temperature $\left(\eta_{0}=0.75\right)$ are shown in figures 3(a) and three for 2004 and 2005, respectively. A comparison of the single ice tracing from 2004 in figure 3(a), and the five ice tracings from 2005 reveals somewhat of a difference in the lower surface accretion aft of the main ice shape. The leading edge ice shape from run 35 in figure 3(a) (2004) looks similar to those in figure 3(b) (2005), but there is a larger protuberance on the lower surface of the airfoil in the 2004 case when compared to the 2005 ice tracings in figure 3(b).

This difference may be due to a slight spanwise gap that existed between adjacent sections of the heater mat installed on the airfoil for the 2004 test. More will be said about this later, but for the purposes of quantifying the repeatability of the nominal condition with the THICK program, this potential artifact does not appear to have significantly affected the horn angles and horn thickness of the main ice shape. Unfortunately the 2004 test was prematurely shortened due to a facilities issue, and repeat runs were not acquired in 2004 to further validate the features seen in the run 35 ice tracing.

\section{Quantitative Evaluation}

The THICK program developed by William Wright of QSS Group, Inc., at NASA Glenn Research Center was used to perform quantitative assessment of changes in ice shape features (ref. 4). This program was originally developed and used during the validation of LEWICE. By comparing the un-iced airfoil coordinates with the digitized coordinates of an ice shape, it is capable of calculating ice shape attributes such as upper and lower surface icing horn ice thickness, icing horn angle, and icing limits.

Figure 4 shows the convention that THICK uses to determine maximum thickness and horn angle. An axis has been superimposed on the ice tracing to illustrate the coordinate system used by THICK to determine the angles of the maximum ice thickness (which THICK considers as horns) on both the upper and lower surface of the airfoil. The maximum thickness is calculated by scanning the ice shape for the location of greatest thickness normal to the surface on both the upper and lower surface of the airfoil. When a maximum thickness is found, THICK then draws a line from the origin of the axis system to the point of maximum thickness, whereupon it then calculates the associated angle as depicted in figure 4 .

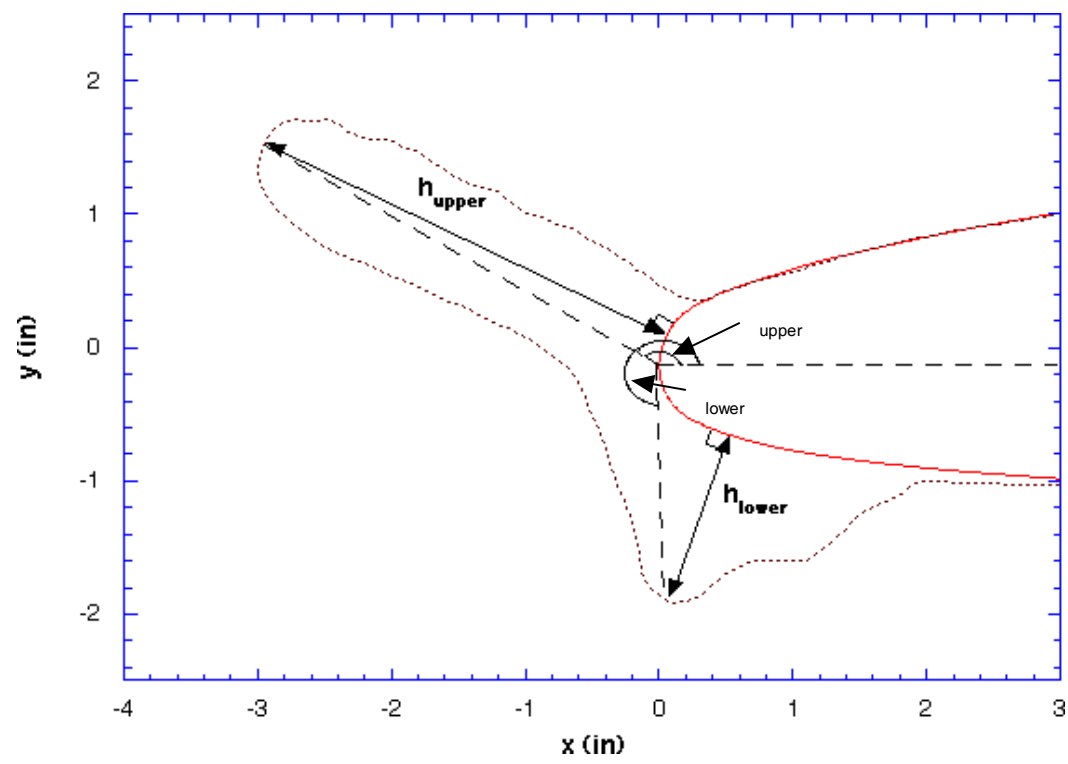

Figure 4.-Diagram showing THICK computation of horn thickness and horn angle. 
THICK was used to determine the upper and lower ice horn thickness and angles associated with the ice tracings shown in figures 3(a) through (d). These results are tabulated in table 2, along with ice shape mass measurements for each of the nominal condition runs, and they will provide the basis for analyzing ice feature changes due to variations in spray conditions.

The THICK ice feature calculations and mass measurements in table 2 have been organized into four sections based on year (2004 or 2005) and freezing fraction $\left(\eta_{0}=0.39\right.$ or 0.75$)$. This was done to develop an average and standard deviation value for the nominal condition ice features which accounts for any year-to-year differences in the test data, or differences due to freezing fraction. Since the focus of this sensitivity study was to investigate ice shape feature changes relative to a nominal condition, it was imperative that the nominal condition ice features be as accurate as possible. Developing an average and standard deviation based on test year and freezing fraction was deemed the best way to accomplish this objective.

TABLE 2.-REPEATABILITY OF THICK CALCULATIONS AND MASS MEASUREMENTS FOR NOMINAL CONDITION

\begin{tabular}{|c|c|c|c|c|c|c|c|c|c|c|c|c|}
\hline Year & run\# & $\eta_{0}$ & $\begin{array}{l}\text { IRT } \\
\text { MVD }\end{array}$ & $\begin{array}{l}\text { IRT } \\
\text { LWC }\end{array}$ & Pair & $\Delta \mathbf{P}$ & AOA & $\begin{array}{l}\text { Lower } \\
\text { Horn } \\
\text { Thick- } \\
\text { ness } \\
\text { (inches) }\end{array}$ & $\begin{array}{l}\text { Upper } \\
\text { Horn } \\
\text { Thick- } \\
\text { ness } \\
\text { (inches) }\end{array}$ & $\begin{array}{c}\text { Lower } \\
\text { Horn } \\
\text { Angle } \\
\text { (deg) }\end{array}$ & $\begin{array}{c}\text { Upper } \\
\text { Horn } \\
\text { Angle } \\
\text { (deg) }\end{array}$ & $\begin{array}{c}\text { Ice } \\
\text { Shape } \\
\text { Mass } \\
\text { (gm) }\end{array}$ \\
\hline \multirow{6}{*}{2004} & 15 & 0.39 & 28.7 & 0.827 & 25 & 120 & 2.5 & 2.13 & 2.54 & 244.0 & 149.0 & 931.0 \\
\hline & 17 & 0.39 & 28.7 & 0.827 & 25 & 120 & 2.5 & 1.88 & 2.18 & 254.0 & 144.0 & 910.9 \\
\hline & 24 & 0.39 & 28.7 & 0.827 & 25 & 120 & 2.5 & 2.05 & 2.21 & 256.0 & 145.0 & 1015.1 \\
\hline & 42 & 0.39 & 28.7 & 0.827 & 25 & 120 & 2.5 & 1.98 & 2.24 & 256.0 & 151.0 & $\mathrm{~N} / \mathrm{A}$ \\
\hline & \multicolumn{7}{|c|}{ Average } & 2.01 & 2.29 & 252.5 & 147.3 & 952.3 \\
\hline & \multicolumn{7}{|c|}{ Standard Deviation } & 0.11 & 0.17 & 5.7 & 3.3 & 55.3 \\
\hline \multirow{7}{*}{2005} & 49 & 0.39 & 28.7 & 0.827 & 25 & 120 & 2.5 & 2.07 & 2.32 & 257.0 & 141.0 & 1140.0 \\
\hline & 133 & 0.39 & 28.7 & 0.827 & 25 & 120 & 2.5 & 2.11 & 2.15 & 255.0 & 141.0 & 1190.0 \\
\hline & 134 & 0.39 & 28.7 & 0.827 & 25 & 120 & 2.5 & 2.03 & 2.36 & 257.0 & 144.0 & 1282.0 \\
\hline & 135 & 0.39 & 28.7 & 0.827 & 25 & 120 & 2.5 & 2.21 & 2.5 & 264.0 & 143.0 & 1252.0 \\
\hline & 136 & 0.39 & 28.7 & 0.827 & 25 & 120 & 2.5 & 2.33 & 2.41 & 251.0 & 141.0 & 1280.0 \\
\hline & \multirow{2}{*}{\multicolumn{7}{|c|}{\begin{tabular}{|l} 
Average \\
Standard Deviation
\end{tabular}}} & 2.15 & 2.35 & 256.8 & 142.0 & 1228.8 \\
\hline & & & & & & & & 0.12 & 0.13 & 4.7 & 1.4 & 62.0 \\
\hline \multirow[t]{2}{*}{2004} & 35 & 0.75 & 28.7 & 0.827 & 25 & 120 & 2.5 & 2.25 & 2.43 & 206.0 & 165.0 & 1400.7 \\
\hline & \multicolumn{7}{|c|}{$\begin{array}{l}\text { Average } \\
\text { Standard Deviation }\end{array}$} & $\begin{array}{c}2.25 \\
* * * *\end{array}$ & $\begin{array}{c}2.43 \\
* * * *\end{array}$ & 206.0 & $\begin{array}{c}165.0 \\
* * * *\end{array}$ & $\begin{array}{c}1400.7 \\
* * * *\end{array}$ \\
\hline \multirow{7}{*}{2005} & 63 & 0.75 & 28.7 & 0.827 & 25 & 120 & 2.5 & 2.32 & 2.43 & 208.0 & 171.0 & 1258.0 \\
\hline & 137 & 0.75 & 28.7 & 0.827 & 25 & 120 & 2.5 & 2.47 & 2.71 & 207.0 & 168.0 & 1408.0 \\
\hline & 138 & 0.75 & 28.7 & 0.827 & 25 & 120 & 2.5 & 2.46 & 2.65 & 207.0 & 168.0 & 1409.0 \\
\hline & 139 & 0.75 & 28.7 & 0.827 & 25 & 120 & 2.5 & 2.33 & 2.65 & 206.0 & 169.0 & 1426.0 \\
\hline & 140 & 0.75 & 28.7 & 0.827 & 25 & 120 & 2.5 & 2.34 & 2.57 & 209.0 & 166.0 & 1415.5 \\
\hline & \multirow{2}{*}{\multicolumn{7}{|c|}{ Average }} & 2.38 & 2.60 & 207.4 & 168.4 & 1383.3 \\
\hline & & & & & & & & 0.07 & 0.11 & 1.1 & 1.8 & 70.4 \\
\hline
\end{tabular}

A closer examination of table 2 reveals several things:

a) There was a notable difference between the 2004 and 2005 Average mass measurements for the warm temperature condition $\left(\eta_{0}=0.39\right)$. This difference was unexpected. The warm temperature 2004 and 2005 ice shapes look very similar qualitatively in figure 3 , as do the corresponding Average horn thickness and angles in table 2 which implies the spray condition was the same in 2004 and 2005. It should be mentioned that the spanwise dimension over which the ice was removed was noted to be 6 percent larger in 2005 than 2004, but that would not completely account for the 29 percent difference seen here. Also, the mass measurements 
were not all acquired on one day in 2004 and 2005, and they appear to be relatively consistent in value. Based on this, we believe there was a possible systematic difference in the ice mass measurement technique for the warm condition between 2004 and 2005. However, we believe that this difference can be accounted for by applying the 2004 average and standard deviation values listed in table 2 to the 2004 data in the analysis process, and likewise for the 2005 data.

b) The 2004 and 2005 Average mass measurements for the cold temperature condition $\left(\eta_{0}=0.75\right)$ had similar values

c) The 2004 and 2005 Average and Standard Deviation values for upper and lower horn thickness, and upper and lower horn angles at $\left(\eta_{0}=0.39\right)$ and also $\left(\eta_{0}=0.75\right)$ were nearly the same in value, which suggests there was good repeatability in the ice tracing data.

d) There was only one nominal condition ice tracing acquired at the cold temperature $\left(\eta_{0}=0.75\right)$ in 2004 , therefore no standard deviation could be calculated.

\section{B. Data Analysis Process}

The overall objective of this study was to investigate changes in ice shape features, due to variations in the icing spray condition. To do this a nominal spray condition $\left(P_{\text {air nom }}=25 \mathrm{psi}, \Delta P_{\text {nom }}=120 \mathrm{psi}\right)$ was selected, and then the values of $P_{\text {air }}$ and $\Delta P$ were varied with respect to this condition. This was done at a warm temperature $\left(T_{\text {tot }}=23^{\circ} \mathrm{F}, T_{s}=13.5^{\circ} \mathrm{F}\right)$ which corresponded to a freezing fraction of $\eta_{0}=0.39$, and a cold temperature $\left(T_{t o t}=7.9^{\circ} \mathrm{F}, T_{s}=-1.6^{\circ} \mathrm{F}\right)$ which corresponded to a freezing fraction of $\eta_{0}=0.75$. Ice shape tracings and mass measurements were then obtained for the nominal condition and for each variant condition. These data were analyzed using the process outlined below:

Step (1).- The THICK program was used to calculate the upper and lower horn thickness, and the upper and lower horn angles from the ice tracings.

Step (2).- The average and standard deviation for the nominal condition ice shape features and the mass measurements was then determined for each temperature condition for 2004 and then for 2005 . This process has already been described in the previous section and results are summarized below in table 2:

Step (3).- The net change in THICK ice shape features for the variant conditions were determined with respect to the nominal condition as a function of each freezing fraction and year. This was accomplished by subtracting off the nominal condition ice feature values, so the "delta" ice feature due to the variant condition could be examined in higher resolution.

a) For variant conditions from 2004 that were acquired at $\eta_{0}=0.39$, the average values in table 2 were subtracted from the corresponding variant THICK ice shape feature value determined in step (1) above. The average ice shape values which were subtracted are listed below for each ice shape feature:
a. Lower horn thickness $=2.01 \mathrm{in}$.
b. Upper horn thickness $=2.29$ in.
c. $\quad$ Lower horn angle $=252.5^{\circ}$
d. Upper horn angle $=147.3^{\circ}$
e. $\quad$ Mass $=952 \mathrm{~g}$

b) For variant conditions from 2004 that were acquired at $\eta_{0}=0.75$, the average values in table 2 were subtracted from the corresponding THICK variant ice shape feature value determined in step (1) above. The average ice shape values which were subtracted are listed below for each ice shape feature:

Lower horn thickness $=2.25$ in.
a. Upper horn thickness $=2.43$ in.
b. Lower horn angle $=206^{\circ}$
c. Upper horn angle $=165^{\circ}$
d. $\quad$ Mass $=1401 \mathrm{~g}$ 
c) For variant conditions from 2005 that were acquired at $\eta_{0}=0.39$, the average values in table 2 were subtracted from the corresponding THICK variant ice shape feature value determined in step (1) above. The average ice shape values which were subtracted are listed below for each ice shape feature:
a. Lower horn thickness $=2.15$ in.
b. Upper horn thickness $=2.35$ in.
c. $\quad$ Lower horn angle $=256.8^{\circ}$
d. Upper horn angle $=142^{\circ}$
e. $\quad$ Mass $=1229 \mathrm{~g}$

d) For variant conditions from 2005 that were acquired at $\eta_{0}=0.75$, the average values in table 2 were subtracted from the corresponding THICK variant ice shape feature value determined in step (1) above. The average ice shape values which were subtracted are listed below for each ice shape feature:
a. Lower horn thickness $=2.38$ in.
b. Upper horn thickness $=2.60 \mathrm{in}$.
c. Lower horn angle $=207.4^{\circ}$
d. Upper horn angle $=168.4^{\circ}$
e. Mass $=1383 \mathrm{~g}$

Step (4).-The net change in ice shape features was then normalized in terms of the corresponding standard deviation for the ice shape parameter. This was done to try to quantify the relative significance of the feature change in terms of normal run-to-run ice shape variability.

a) For variant conditions $\eta_{0}=0.39$, the net ice shape feature change determined in step (3) was divided by the average of the corresponding standard deviation values from 2004 and 2005 in table 2 . The normalization values for $\eta_{0}=0.39$ are listed below for each ice shape feature:
a. Lower horn thickness $=(0.11+0.12) / 2=0.115$ in
b. Upper horn thickness $=(0.17+0.13) / 2=0.15$ in.
c. Lower horn angle $=(5.7+4.7) / 2=5.2^{\circ}$
d. Upper horn angle $=(3.3+1.4) / 2=2.25^{\circ}$
e. $\quad$ Mass $=(55+62) / 2=59 \mathrm{~g}$

b) For variant conditions acquired at $\eta_{0}=0.75$, the net ice shape feature change determined in step (3) was divided by the standard deviation values from 2005 in table 2 . No standard deviation was available for the 2004 nominal case, so the 2005 nominal results were used in lieu of an average value. The normalization values for $\eta_{0}=0.75$ are listed below for each ice shape feature:
a. Lower horn thickness $=0.07$ in.
b. Upper horn thickness $=0.11$ in.
c. $\quad$ Lower horn angle $=1.1^{\circ}$
d. Upper horn angle $=1.8^{\circ}$
e. Mass $=70 \mathrm{~g}$

Step (5).-The change in spray condition parameters was determined with respect to the nominal condition parameters $\left(P_{\text {air nom }}=25 \mathrm{psi}, \Delta P_{\text {nom }}=120 \mathrm{psi}, L W C_{\text {nom }}=0.827 \mathrm{~g} / \mathrm{m}^{3}, M V D_{\text {nom }}=28.7 \mu \mathrm{m}\right)$. The resulting values represented the net change in the spray parameters with respect to the nominal spray condition.

This was accomplished by:

a) subtracting 25 psi from each variant condition $P_{\text {air }}$ value

b) subtracting $120 \mathrm{psi}$ from each variant condition $\Delta P$ value 
c) subtracting. $0.827 \mathrm{~g} / \mathrm{m}^{3}$ from each variant condition $L W C$ value

d) subtracting $28.7 \mu \mathrm{m}$ from each variant condition $M V D$ value

Step (6).- - The results of steps (3) through (5) were then tabulated and quality controlled by inspecting the tabular values of net ice feature changes and looking for inconsistencies. If an inconsistency was identified, then ice tracing plots, THICK program files, and IRT tunnel data logs were reviewed to resolve the inconsistency. If the inconsistency could not be satisfactorily resolved, those data values were not used to develop contour plots. The quality controlled data are tabulated in tables 3 and 4 .

TABLE 3.-ICE SHAPE FEATURE MEASUREMENTS

\begin{tabular}{|c|c|c|c|c|c|c|c|c|c|c|c|}
\hline \multirow[b]{2}{*}{ run\# } & \multirow[b]{2}{*}{ Run Date } & \multirow[b]{2}{*}{$\eta$} & \multirow[b]{2}{*}{$\begin{array}{l}\text { MVD } \\
(\mu \mathrm{m}) \\
\end{array}$} & \multirow[b]{2}{*}{$\begin{array}{c}\text { LWC } \\
\left(\mathrm{g} / \mathrm{m}^{3}\right)\end{array}$} & \multirow[b]{2}{*}{$\begin{array}{l}\text { Pair } \\
\text { (psi) }\end{array}$} & \multirow[b]{2}{*}{$\begin{array}{c}\Delta \mathrm{P} \\
(\mathrm{psi})\end{array}$} & \multicolumn{5}{|c|}{ Step(1) } \\
\hline & & & & & & & $\begin{array}{c}\text { Lower Horn } \\
\text { Thickness } \\
\text { (inches) }\end{array}$ & $\begin{array}{c}\text { Upper Horn } \\
\text { Thickness } \\
\text { (inches) }\end{array}$ & $\begin{array}{c}\text { Lower Horn } \\
\text { Angle } \\
\text { (degrees) }\end{array}$ & $\begin{array}{l}\text { Upper Horn } \\
\text { Angle } \\
\text { (degrees) }\end{array}$ & $\begin{array}{c}\text { Mass } \\
(\mathrm{gm})\end{array}$ \\
\hline 19 & $8 / 31 / 2004$ & 0.39 & 38.9 & 0.985 & 25 & $\frac{170}{170}$ & 2.20 & 2.28 & 262 & 128 & $\frac{1599}{1399.5}$ \\
\hline 20 & $8 / 31 / 2004$ & 0.39 & 36.7 & 0.955 & 25 & 160 & 2.18 & 2.37 & 267 & 133 & 1316.8 \\
\hline 21 & $8 / 31 / 2004$ & 0.39 & 34.6 & 0.925 & 25 & 150 & 2.09 & 2.34 & 267 & 138 & 1227.9 \\
\hline 22 & $8 / 31 / 2004$ & 0.39 & 32.6 & 0.893 & 25 & 140 & 2.17 & 2.33 & 264 & 141 & 1156.4 \\
\hline 23 & $8 / 31 / 2004$ & 0.39 & 30.6 & 0.861 & 25 & 130 & 2.06 & 2.22 & 258 & 144 & 1070.5 \\
\hline 24 & $8 / 31 / 2004$ & 0.39 & 28.7 & 0.827 & 25 & 120 & 2.05 & 2.21 & 256 & 145 & 1015.1 \\
\hline 25 & $8 / 31 / 2004$ & 0.39 & 26.9 & 0.791 & 25 & 110 & 1.82 & 2.05 & 252 & 145 & 871.5 \\
\hline 26 & \begin{tabular}{|l} 
9/1/2004 \\
\end{tabular} & 0.39 & 20.2 & 0.629 & 25 & 70 & 1.50 & 1.60 & 248 & 162 & 554.0 \\
\hline 27 & \begin{tabular}{|l|} 
9/1/2004 \\
\end{tabular} & 0.39 & 21.8 & 0.674 & 25 & 80 & 1.41 & 1.58 & 248 & 156 & 628.0 \\
\hline 28 & \begin{tabular}{|l|l|}
$9 / 1 / 2004$ \\
\end{tabular} & 0.39 & 23.5 & 0.715 & 25 & 90 & 1.80 & 2.01 & 244 & 155 & 710.5 \\
\hline 29 & \begin{tabular}{|l|}
$9 / 1 / 2004$ \\
\end{tabular} & 0.39 & 25.2 & 0.754 & 25 & 100 & 1.82 & 1.81 & 245 & 151 & 770.5 \\
\hline 42 & \begin{tabular}{|l|}
$/ 3 / 2004$ \\
\end{tabular} & 0.39 & 28.7 & 0.827 & 25 & 120 & 1.98 & 2.24 & 256 & 151 & $\mathrm{n} / \mathrm{a}$ \\
\hline 43 & \begin{tabular}{|l|l}
$9 / 3 / 2004$ \\
\end{tabular} & 0.39 & 21.3 & 0.753 & 30 & 100 & 1.87 & 1.92 & 240 & 160 & 679.4 \\
\hline 44 & \begin{tabular}{|l|l}
$9 / 3 / 2004$ \\
\end{tabular} & 0.39 & 23.1 & 0.888 & 35 & 140 & 1.80 & 2.13 & 249 & 149 & 837.0 \\
\hline 45 & $9 / 3 / 2004$ & 0.39 & 23.9 & 0.825 & 30 & 120 & 2.02 & 2.15 & 252 & 157 & 813.8 \\
\hline 46 & \begin{tabular}{|l|}
$9 / 3 / 2004$ \\
\end{tabular} & 0.39 & 26.5 & 0.979 & 35 & 170 & 2.11 & 2.42 & 253 & 146 & 1043.3 \\
\hline 47 & \begin{tabular}{|l|l|}
$9 / 3 / 2004$ \\
\end{tabular} & 0.39 & 26.7 & 0.892 & 30 & 140 & 2.14 & 2.26 & 253 & 149 & 964.3 \\
\hline 49 & $2 / 1 / 2005$ & 0.39 & 28.7 & 0.827 & 25 & 120 & 2.07 & 2.32 & 257 & 141 & 1140.4 \\
\hline 50 & \begin{tabular}{|l|l|}
$2 / 1 / 2005$ \\
\end{tabular} & 0.39 & 25.1 & 0.628 & 20 & 70 & 1.72 & 1.84 & 244 & 149 & 795.8 \\
\hline 51 & $2 / 1 / 2005$ & 0.39 & 27.5 & 0.672 & 20 & 80 & 1.92 & 2.10 & 252 & 149 & 906.7 \\
\hline 52 & $2 / 1 / 2005$ & 0.39 & 29.9 & 0.714 & 20 & 90 & 2.06 & 2.25 & 248 & 139 & 1038.0 \\
\hline 53 & $2 / 1 / 2005$ & 0.39 & 32.4 & 0.753 & 20 & 100 & 2.21 & 2.43 & 249 & 143 & 1144.9 \\
\hline 54 & $2 / 1 / 2005$ & 0.39 & 21.3 & 0.753 & 30 & 100 & 1.89 & 2.03 & 242 & 156 & 814.7 \\
\hline 55 & \begin{tabular}{|l} 
\\
$2 / 1 / 2005$ \\
\end{tabular} & 0.39 & 23.9 & 0.825 & 30 & 120 & 2.02 & 2.28 & 246 & 147 & 976.6 \\
\hline 56 & $2 / 1 / 2005$ & 0.39 & 26.7 & 0.892 & 30 & 140 & 2.13 & 2.40 & 256 & 138 & 1198.5 \\
\hline 57 & $2 / 1 / 2005$ & 0.39 & 29.6 & 0.954 & 30 & 160 & 2.22 & 2.41 & 268 & 141 & 1410.0 \\
\hline 58 & $2 / 2 / 2005$ & 0.39 & 32.9 & 1.012 & 30 & 180 & 2.33 & 2.39 & 264 & 129 & 1558.3 \\
\hline 59 & $2 / 2 / 2005$ & 0.39 & 23.1 & 0.888 & 35 & 140 & 2.00 & 2.23 & 245 & 148 & 1030.3 \\
\hline 60 & $\begin{array}{l}2 / 2 / 2005 \\
\end{array}$ & 0.39 & 26.5 & 0.979 & 35 & 170 & 2.38 & 2.45 & 251 & 140 & 1298.7 \\
\hline 61 & \begin{tabular}{|l|l|}
$2 / 2 / 2005$ \\
\end{tabular} & 0.39 & 21.6 & 0.912 & 40 & 150 & 1.97 & 2.26 & 247 & 149 & 998.9 \\
\hline 62 & $\begin{array}{l}2 / 2 / 2005 \\
\end{array}$ & 0.39 & 24.4 & 0.999 & 40 & 180 & 2.29 & 2.57 & 249 & 142 & 1270.8 \\
\hline 78 & $2 / 4 / 2005$ & 0.39 & 35.5 & 0.625 & 15 & 70 & 2.07 & 2.19 & 214 & 164 & 1257.7 \\
\hline 83 & $2 / 24 / 2005$ & 0.39 & 28.2 & 0.527 & 15 & 50 & 1.6 & 1.72 & 247 & 152 & 692 \\
\hline 84 & $2 / 24 / 2005$ & 0.39 & 31.8 & 0.578 & 15 & 60 & 1.73 & 1.86 & 242 & 145 & 885 \\
\hline 85 & $2 / 24 / 2005$ & 0.39 & 39.4 & 0.669 & 15 & 80 & 1.86 & 2.21 & 248 & 140 & 1190 \\
\hline 133 & $9 / 8 / 2005$ & 0.39 & 28.7 & 0.827 & 25 & 120 & 2.11 & 2.15 & 255 & 141 & 1190 \\
\hline 134 & $9 / 8 / 2005$ & 0.39 & 28.7 & 0.827 & 25 & 120 & 2.03 & 2.36 & 257 & 144 & 1282 \\
\hline 135 & $\begin{array}{l}/ 8 / 2005 \\
\end{array}$ & 0.39 & 28.7 & 0.827 & 25 & 120 & 2.21 & 2.5 & 267 & 143 & 1252 \\
\hline 136 & \begin{tabular}{|l}
$9 / 8 / 2005$ \\
\end{tabular} & 0.39 & 28.7 & 0.827 & 25 & 120 & 2.33 & 2.41 & 251 & 141 & 1280 \\
\hline 30 & 9/1/2004 & 0.75 & 20.2 & 0.629 & 25 & 70 & 1.16 & 1.25 & 198 & 168 & 762.0 \\
\hline 31 & \begin{tabular}{|l|} 
9/1/2004 \\
\end{tabular} & 0.75 & 21.8 & 0.674 & 25 & 80 & 1.26 & 1.36 & 202 & 164 & 825.0 \\
\hline 32 & \begin{tabular}{|l|l|}
$9 / 1 / 2004$ \\
\end{tabular} & 0.75 & 23.5 & 0.715 & 25 & 90 & 1.38 & 1.39 & 205 & 167 & 930.0 \\
\hline 33 & \begin{tabular}{|l|}
$9 / 1 / 2004$ \\
\end{tabular} & 0.75 & 25.2 & 0.754 & 25 & 100 & 1.77 & 1.74 & 207 & 171 & 1017.5 \\
\hline 34 & \begin{tabular}{|l|l|} 
\\
\end{tabular} & 0.75 & 26.9 & 0.791 & 25 & 110 & 1.97 & 1.87 & 207 & 170 & 1147.0 \\
\hline 35 & \begin{tabular}{|l|l|}
$9 / 2 / 2004$ \\
\end{tabular} & 0.75 & 28.7 & 0.827 & 25 & 120 & 2.32 & 2.43 & 208 & 174 & 1257.5 \\
\hline 40 & 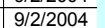 & 0.75 & 20.2 & 0.629 & 25 & 70 & 1.28 & 1.33 & 198 & 171 & 725.5 \\
\hline 63 & $2 / 2 / 2005$ & 0.75 & 28.7 & 0.827 & 25 & 120 & 2.25 & 2.43 & 206 & 165 & 1400.7 \\
\hline 64 & $2 / 2 / 2005$ & 0.75 & 25.1 & 0.628 & 20 & 70 & 1.68 & 1.75 & 210 & 182 & 1027.6 \\
\hline 65 & $2 / 2 / 2005$ & 0.75 & 27.5 & 0.672 & 20 & 80 & 2.03 & 2.13 & 214 & 172 & 1141.4 \\
\hline 66 & $2 / 2 / 2005$ & 0.75 & 29.9 & 0.714 & 20 & 90 & 1.98 & 2.16 & 213 & 170 & 1235.0 \\
\hline 67 & $2 / 3 / 2005$ & 0.75 & 32.4 & 0.753 & 20 & 100 & 2.24 & 2.30 & 213 & 170 & 1343.8 \\
\hline 68 & $2 / 3 / 2005$ & 0.75 & 21.3 & 0.753 & 30 & 100 & 1.55 & 1.79 & 224 & 183 & 975.6 \\
\hline 69 & $2 / 3 / 2005$ & 0.75 & 23.9 & 0.825 & 30 & 120 & 2.06 & 2.26 & 209 & 169 & 1128.2 \\
\hline 70 & $2 / 3 / 2005$ & 0.75 & 26.7 & 0.892 & 30 & 140 & 2.18 & 2.32 & 205 & 164 & 1283.9 \\
\hline 71 & $2 / 3 / 2005$ & 0.75 & 29.6 & 0.954 & 30 & 160 & 2.48 & 2.71 & 214 & 169 & 1455.0 \\
\hline 72 & $2 / 3 / 2005$ & 0.75 & 32.9 & 1.012 & 30 & 180 & 2.78 & 2.98 & 210 & 168 & 1611.3 \\
\hline 73 & $2 / 3 / 2005$ & 0.75 & 23.1 & 0.888 & 35 & 140 & 2.20 & 2.34 & 210 & 170 & 1109.7 \\
\hline 74 & $\begin{array}{l}/ 3 / 2005 \\
\end{array}$ & 0.75 & 26.5 & 0.979 & 35 & 170 & 2.45 & 2.74 & 209 & 169 & 1318.5 \\
\hline 79 & $2 / 4 / 2005$ & 0.75 & 35.0 & 0.790 & 20 & 110 & 2.45 & 2.58 & 213 & 169 & 1551.5 \\
\hline 80 & $2 / 4 / 2005$ & 0.75 & 36.7 & 0.955 & 25 & 160 & 2.91 & 3.08 & 213 & 171 & 1775.7 \\
\hline 81 & $2 / 4 / 2005$ & 0.75 & 21.6 & 0.912 & 40 & 150 & 2.16 & 2.20 & 209 & 178 & 1066.3 \\
\hline 87 & $2 / 24 / 2005$ & 0.75 & 28.2 & 0.527 & 15 & 50 & 1.48 & 1.48 & 207 & 182 & 920 \\
\hline 88 & $2 / 24 / 2005$ & 0.75 & 31.8 & 0.578 & 15 & 60 & 1.96 & 2.02 & 212 & 179 & 1137 \\
\hline 89 & $2 / 24 / 2005$ & 0.75 & 39.4 & 0.669 & 15 & 80 & 2.36 & 2.51 & 208 & 171 & 1570 \\
\hline 137 & 9/8/2005 & 0.75 & 28.7 & 0.827 & 25 & 120 & 2.47 & 2.71 & 207 & 168 & 1408 \\
\hline 138 & \begin{tabular}{|l}
$9 / 8 / 2005$ \\
\end{tabular} & 0.75 & 28.7 & 0.827 & 25 & 120 & 2.46 & 2.65 & 207 & 168 & 1409 \\
\hline 139 & \begin{tabular}{|l|l} 
& $9 / 8 / 2005$ \\
\end{tabular} & 0.75 & 28.7 & 0.827 & 25 & 120 & 2.33 & 2.65 & 206 & 169 & 1426 \\
\hline 140 & \begin{tabular}{|l|}
$9 / 8 / 2005$ \\
\end{tabular} & 0.75 & 28.7 & 0.827 & 25 & 120 & 2.34 & 2.57 & 209 & 166 & 1415.5 \\
\hline
\end{tabular}

Data from step (1) of the data analysis process. 
TABLE 4.-NORMALIZED ICE SHAPE FEATURE CHANGES

\begin{tabular}{|c|c|c|c|c|c|c|c|c|c|c|c|}
\hline \multirow[b]{2}{*}{ run\# } & \multirow[b]{2}{*}{ Run Date } & \multirow[b]{2}{*}{$\eta$} & \multirow[b]{2}{*}{$\begin{array}{l}\text { Lower Horn } \\
\text { Thickness } \\
\text { (std dev) }\end{array}$} & \multirow[b]{2}{*}{$\begin{array}{l}\text { Upper Horn } \\
\text { Thickness } \\
\text { (std dev) }\end{array}$} & \multirow{2}{*}{\begin{tabular}{|c|} 
Step(4) \\
Lower Horn \\
Angle \\
(std dev) \\
\end{tabular}} & \multirow[b]{2}{*}{$\begin{array}{c}\text { Upper Horn } \\
\text { Angle } \\
\text { (std dev) }\end{array}$} & \multirow[b]{2}{*}{$\begin{array}{c}\text { Mass } \\
\text { (std dev) }\end{array}$} & & & Step(5) & \\
\hline & & & & & & & & $\begin{array}{c}\text { Pair-25 } \\
\text { (psi) }\end{array}$ & $\begin{array}{c}\Delta \mathrm{P}-120 \\
(\mathrm{psi})\end{array}$ & $\begin{array}{c}\text { MVD - } 28.7 \\
(\mu \mathrm{m})\end{array}$ & $\begin{array}{c}\text { LWC - } 0.827 \\
(\mathrm{~g} / \mathrm{m} 3)\end{array}$ \\
\hline 19 & $8 / 31 / 2004$ & 0.39 & 1.65 & -0.08 & 1.83 & -8.56 & \begin{tabular}{|c|}
7.58 \\
\end{tabular} & \begin{tabular}{|c|} 
(1) \\
0
\end{tabular} & 50 & \begin{tabular}{|l|}
10.2 \\
\end{tabular} & \begin{tabular}{|l|}
0.158 \\
\end{tabular} \\
\hline 20 & $8 / 31 / 2004$ & 0.39 & 1.48 & 0.52 & 2.79 & -6.33 & 6.18 & 0 & 40 & 8 & 0.128 \\
\hline 21 & $8 / 31 / 2004$ & 0.39 & 0.70 & 0.32 & 2.79 & -4.11 & 4.67 & 0 & 30 & 5.9 & 0.098 \\
\hline 22 & $8 / 31 / 2004$ & 0.39 & 1.39 & 0.25 & 2.21 & -2.78 & 3.46 & 0 & 20 & 3.9 & 0.066 \\
\hline 23 & $8 / 31 / 2004$ & 0.39 & 0.43 & -0.48 & 1.06 & -1.44 & 2.00 & 0 & 10 & 1.9 & 0.034 \\
\hline 24 & $8 / 31 / 2004$ & 0.39 & 0.35 & -0.55 & 0.67 & -1.00 & 1.06 & 0 & 0 & 0 & 0 \\
\hline 25 & $8 / 31 / 2004$ & 0.39 & -1.65 & -1.62 & -0.10 & -1.00 & -1.37 & 0 & -10 & -1.8 & -0.036 \\
\hline 26 & $9 / 1 / 2004$ & 0.39 & -4.43 & -4.62 & -0.87 & 6.56 & -6.75 & 0 & -50 & -8.5 & -0.198 \\
\hline 27 & $9 / 1 / 2004$ & 0.39 & -5.22 & -4.75 & -0.87 & 3.89 & -5.50 & 0 & -40 & -6.9 & -0.153 \\
\hline 28 & 9/1/2004 & 0.39 & -1.83 & -1.88 & -1.63 & 3.44 & -4.10 & 0 & -30 & -5.2 & -0.112 \\
\hline 29 & $9 / 1 / 2004$ & 0.39 & -1.65 & -3.22 & -1.44 & 1.67 & -3.08 & 0 & -20 & -3.5 & -0.073 \\
\hline 42 & $9 / 3 / 2004$ & 0.39 & -0.26 & -0.35 & 0.67 & 1.67 & $\mathrm{n} / \mathrm{a}$ & 0 & 0 & 0 & 0 \\
\hline 43 & $9 / 3 / 2004$ & 0.39 & -1.22 & -2.48 & -2.40 & 5.67 & -4.63 & 5 & -20 & -7.4 & -0.074 \\
\hline 44 & $9 / 3 / 2004$ & 0.39 & -1.83 & -1.08 & -0.67 & 0.78 & -1.95 & 10 & 20 & -5.6 & 0.061 \\
\hline 45 & $9 / 3 / 2004$ & 0.39 & 0.09 & -0.95 & -0.10 & 4.33 & -2.35 & 5 & 0 & -4.8 & -0.002 \\
\hline 46 & $9 / 3 / 2004$ & 0.39 & 0.87 & 0.85 & 0.10 & -0.56 & 1.54 & 10 & 50 & -2.2 & 0.152 \\
\hline 47 & $9 / 3 / 2004$ & 0.39 & 1.13 & -0.22 & 0.10 & 0.78 & 0.20 & 5 & 20 & -2 & 0.065 \\
\hline 49 & $2 / 1 / 2005$ & 0.39 & -0.70 & -0.19 & 0.04 & -0.44 & -1.50 & 0 & 0 & 0 & 0 \\
\hline 50 & $2 / 1 / 2005$ & 0.39 & -3.74 & -3.39 & -2.46 & 3.11 & -7.34 & -5 & -50 & -3.6 & -0.199 \\
\hline 51 & $2 / 1 / 2005$ & 0.39 & -2.00 & -1.65 & -0.92 & 3.11 & -5.46 & -5 & -40 & -1.2 & -0.155 \\
\hline 52 & $2 / 1 / 2005$ & 0.39 & -0.78 & -0.65 & -1.69 & -1.33 & -3.23 & -5 & -30 & 1.2 & -0.113 \\
\hline 53 & $2 / 1 / 2005$ & 0.39 & 0.52 & 0.55 & -1.50 & 0.44 & -1.42 & -5 & -20 & 3.7 & -0.074 \\
\hline 54 & $2 / 1 / 2005$ & 0.39 & -2.26 & -2.12 & -2.85 & 6.22 & -7.02 & 5 & -20 & -7.4 & -0.074 \\
\hline 55 & $2 / 1 / 2005$ & 0.39 & -1.13 & -0.45 & -2.08 & 2.22 & -4.27 & 5 & 0 & -4.8 & -0.002 \\
\hline 56 & $2 / 1 / 2005$ & 0.39 & -0.17 & 0.35 & -0.15 & -1.78 & -0.51 & 5 & 20 & -2 & 0.065 \\
\hline 57 & $2 / 1 / 2005$ & 0.39 & 0.61 & 0.41 & 2.15 & -0.44 & 3.07 & 5 & 40 & 0.9 & 0.127 \\
\hline 58 & $2 / 2 / 2005$ & 0.39 & 1.57 & 0.28 & 1.38 & -5.78 & 5.58 & 5 & 60 & 4.2 & 0.185 \\
\hline 59 & $2 / 2 / 2005$ & 0.39 & -1.30 & -0.79 & -2.27 & 2.67 & -3.36 & 10 & 20 & -5.6 & 0.061 \\
\hline 60 & $2 / 2 / 2005$ & 0.39 & 2.00 & 0.68 & -1.12 & -0.89 & 1.18 & 10 & 50 & -2.2 & 0.152 \\
\hline 61 & $2 / 2 / 2005$ & 0.39 & -1.57 & -0.59 & -1.88 & 3.11 & -3.90 & 15 & 30 & -7.1 & 0.085 \\
\hline 62 & $2 / 2 / 2005$ & 0.39 & 1.22 & 1.48 & -1.50 & 0.00 & 0.71 & 15 & 60 & -4.3 & 0.172 \\
\hline 78 & $2 / 4 / 2005$ & 0.39 & -0.70 & -1.05 & -8.23 & 9.78 & 0.49 & -10 & -50 & 6.8 & -0.202 \\
\hline 83 & $2 / 24 / 2005$ & 0.39 & -4.78 & -4.19 & -1.88 & 4.44 & -9.10 & -10 & -70 & -0.5 & -0.3 \\
\hline 84 & $2 / 24 / 2005$ & 0.39 & -3.65 & -3.25 & -2.85 & 1.33 & -5.83 & -10 & -60 & 3.1 & -0.249 \\
\hline 85 & $2 / 24 / 2005$ & 0.39 & -2.52 & -0.92 & -1.69 & -0.89 & -0.66 & -10 & -40 & 10.7 & -0.158 \\
\hline 133 & $9 / 8 / 2005$ & 0.39 & -0.35 & -1.32 & -0.35 & -0.44 & -0.66 & 0 & 0 & 0 & 0 \\
\hline 134 & $9 / 8 / 2005$ & 0.39 & -1.04 & 0.08 & 0.04 & 0.89 & 0.90 & 0 & 0 & 0 & 0 \\
\hline 135 & $9 / 8 / 2005$ & 0.39 & 0.52 & 1.01 & 1.96 & 0.44 & 0.39 & 0 & 0 & 0 & 0 \\
\hline 136 & 9/8/2005 & 0.39 & 1.57 & 0.41 & -1.12 & -0.44 & 0.87 & 0 & 0 & 0 & 0 \\
\hline 30 & $9 / 1 / 2004$ & 0.75 & -15.57 & -10.73 & -7.27 & 1.67 & -9.12 & 0 & -50 & -8.5 & -0.198 \\
\hline 31 & 9/1/2004 & 0.75 & -14.14 & -9.73 & -3.64 & -0.56 & -8.22 & 0 & -40 & -6.9 & -0.153 \\
\hline 32 & $9 / 1 / 2004$ & 0.75 & -12.43 & -9.45 & -0.91 & 1.11 & -6.72 & 0 & -30 & -5.2 & -0.112 \\
\hline 33 & $9 / 1 / 2004$ & 0.75 & -6.86 & -6.27 & 0.91 & 3.33 & -5.47 & 0 & -20 & -3.5 & -0.073 \\
\hline 34 & $9 / 1 / 2004$ & 0.75 & -4.00 & -5.09 & 0.91 & 2.78 & -3.62 & 0 & -10 & -1.8 & -0.036 \\
\hline 35 & $9 / 2 / 2004$ & 0.75 & 1.00 & 0.00 & 1.82 & 5.00 & -2.05 & 0 & 0 & 0 & 0 \\
\hline 40 & $9 / 2 / 2004$ & 0.75 & -13.86 & -10.00 & -7.27 & 3.33 & -9.65 & 0 & -50 & -8.5 & -0.198 \\
\hline 63 & $2 / 2 / 2005$ & 0.75 & -1.91 & -1.56 & -1.27 & -1.89 & 0.25 & 0 & 0 & 0 & 0 \\
\hline 64 & $2 / 2 / 2005$ & 0.75 & -10.06 & -7.75 & 2.36 & 7.56 & -5.08 & -5 & -50 & -3.6 & -0.199 \\
\hline 65 & $2 / 2 / 2005$ & 0.75 & -5.06 & -4.29 & 6.00 & 2.00 & -3.46 & -5 & -40 & -1.2 & -0.155 \\
\hline 66 & $2 / 2 / 2005$ & 0.75 & -5.77 & -4.02 & 5.09 & 0.89 & -2.12 & -5 & -30 & 1.2 & -0.113 \\
\hline 67 & $2 / 3 / 2005$ & 0.75 & -2.06 & -2.75 & 5.09 & 0.89 & -0.56 & -5 & -20 & 3.7 & -0.074 \\
\hline 68 & $2 / 3 / 2005$ & 0.75 & -11.91 & -7.38 & 15.09 & 8.11 & -5.82 & 5 & -20 & -7.4 & -0.074 \\
\hline 69 & $2 / 3 / 2005$ & 0.75 & -4.63 & -3.11 & 1.45 & 0.33 & -3.64 & 5 & 0 & -4.8 & -0.002 \\
\hline 70 & $2 / 3 / 2005$ & 0.75 & -2.91 & -2.56 & -2.18 & -2.44 & -1.42 & 5 & 20 & -2 & 0.065 \\
\hline 71 & $2 / 3 / 2005$ & 0.75 & 1.37 & 0.98 & 6.00 & 0.33 & 1.02 & 5 & 40 & 0.9 & 0.127 \\
\hline 72 & $2 / 3 / 2005$ & 0.75 & 5.66 & 3.44 & 2.36 & -0.22 & 3.26 & 5 & 60 & 4.2 & 0.185 \\
\hline 73 & $2 / 3 / 2005$ & 0.75 & -2.63 & -2.38 & 2.36 & 0.89 & -3.91 & 10 & 20 & -5.6 & 0.061 \\
\hline 74 & $2 / 3 / 2005$ & 0.75 & 0.94 & 1.25 & 1.45 & 0.33 & -0.93 & 10 & 50 & -2.2 & 0.152 \\
\hline 79 & $2 / 4 / 2005$ & 0.75 & 0.94 & -0.20 & 5.09 & 0.33 & 2.40 & -5 & -10 & 6.3 & -0.037 \\
\hline 80 & $2 / 4 / 2005$ & 0.75 & 7.51 & 4.35 & 5.09 & 1.44 & 5.61 & 0 & 40 & 8 & 0.128 \\
\hline 81 & $2 / 4 / 2005$ & 0.75 & -3.24 & -3.65 & 1.85 & 5.33 & -4.53 & 15 & 30 & -7.1 & 0.085 \\
\hline 87 & $2 / 24 / 2005$ & 0.75 & -12.91 & -10.20 & -0.36 & 7.56 & -6.62 & -10 & -70 & -0.5 & -0.3 \\
\hline 88 & $2 / 24 / 2005$ & 0.75 & -6.06 & -5.29 & 4.18 & 5.89 & -3.52 & -10 & -60 & 3.1 & -0.249 \\
\hline 89 & $2 / 24 / 2005$ & 0.75 & -0.34 & -0.84 & 0.55 & 1.44 & 2.67 & -10 & -40 & 10.7 & -0.158 \\
\hline 137 & $9 / 8 / 2005$ & 0.75 & 1.23 & 0.98 & -0.36 & -0.22 & 0.35 & 0 & 0 & 0 & 0 \\
\hline 138 & $9 / 8 / 2005$ & 0.75 & 1.09 & 0.44 & -0.36 & -0.22 & 0.37 & 0 & 0 & 0 & 0 \\
\hline 139 & 9/8/2005 & 0.75 & -0.77 & 0.44 & -1.27 & 0.33 & 0.61 & 0 & 0 & 0 & 0 \\
\hline 140 & $9 / 8 / 2005$ & 0.75 & -0.63 & -0.29 & 1.45 & -1.33 & 0.46 & 0 & 0 & 0 & 0 \\
\hline
\end{tabular}

Results from steps (4) and (5) of the data analysis process.

Step (7).- The final step in the analysis process was to develop contour plots from the normalized ice feature data generated in step (4). It was desired to graphically show the extent to which an ice feature varied (e.g., mass, horn angle, and horn thickness) as spray conditions were varied about our nominal condition $\left(P_{\text {air nom }}=25 \mathrm{psi}, \Delta P_{\text {nom }}=120 \mathrm{psi}, L W C_{\text {nom }}=0.827 \mathrm{~g} / \mathrm{m}^{3}, M V D=28.7 \mu \mathrm{m}\right)$.

Figure 2 shows the set of discrete spray conditions used in this test, plotted versus their corresponding $L W C$ and $M V D$. When spray conditions were varied from our nominal condition, this resulted in $L W C$ and $M V D$ changes, which then produced changes in the ice accretion features. For each variant spray condition the changes in ice horn thickness, ice horn angle, and mass were determined, and then correlated with the corresponding change in $L W C$ and $M V D$ (table 4). 
The goal of this data processing step was to develop contour plots using the data in table 4, which would graphically illustrate the ice feature variation. This required a three-dimensional plotting capability where one-dimension represented the change in $M V D$, another dimension represented the change in $L W C$, and the third dimension represented the change in ice feature.

Matlab $^{\mathrm{TM}}$ was used to plot the ice feature changes as a function of changes in $L W C$ and $M V D$ for each condition in table 4. One of Matlab's unique attributes was it's ability to generate a two-dimensional contour plot from a two-dimensional grid of data points, and then use color to illustrate the change in a third parameter associated with each data point. Contour plots were generated to visualize changes in 1) ice accretion mass, 2) lower and upper ice horn angles, and 3) lower and upper ice horn thickness as a function of spray condition variation.

\section{Results and Discussion}

\section{A. Overview}

This section will present the results of this second sensitivity study, which attempted to "map" ice feature changes about a nominal condition $\left(P_{\text {air nom }}=25 \mathrm{psi}, \Delta P_{\text {nom }}=120 \mathrm{psi}, L W C_{\text {nom }}=0.827 \mathrm{~g} / \mathrm{m}^{3}\right.$, $M V D=28.7 \mu \mathrm{m})$. The nominal condition was chosen because it was centrally located within the envelope of the IRT MOD-1 nozzle spray conditions, also placing it within the boundaries of appendix $\mathrm{C}$ icing conditions. Though our original intent for conducting these sensitivity studies was to support the development of instrumentation and simulation requirements for SLD icing conditions, we realized that we needed to conduct more detailed ice shape sensitivity studies in appendix C first. This would enable us to develop methods and understand the nuances associated with ice shape sensitivity in a relatively familiar icing regime first, before proceeding on to evaluate ice shape sensitivity in SLD conditions which constitute a less familiar environment.

\section{B. Data Considerations}

Though ice shapes were acquired at all the test conditions listed in figure 2, a quality control process was used to eliminate cases with inconsistencies. One inconsistency in the data that appeared to affect four runs in 2004 at $\eta_{0}=0.75$, was due to a slight span-wise discontinuity in the surface where heater segments were butted together. The original one piece heater had been removed prior to the test, and a new heater installed. Since, the original heater material was not available; several smaller heater sections were joined together (fig. 5).

After an inspection of 2004 and 2005 ice shape tracings, it became apparent that this gap was affecting the lower surface ice shape for the 2004 larger $M V D$ cases at $\eta_{0}=0.75$. Figure 3(a), is a nominal condition $(M V D=28.7 \mu \mathrm{m})$ ice tracing at the cold test condition, and the squared off feather aft of the main ice shape is becoming visible.

After additional review and comparison against 2005 ice tracings obtained at $\eta_{0}=0.75$ with $M V D$ greater than $28.7 \mu \mathrm{m}$, it was decided to remove these tracings from the ice shape sensitivity database, because the lower surface feature was excessive. However, it was decided to leave the 2004 nominal $28.7 \mu \mathrm{m}$ case shown in figure 3(a) in the database, because when plotted against the 2005 nominal condition ice tracings obtained at $\eta_{0}=0.75$ (shown in fig. 3(b)), it did not seem as pronounced. 


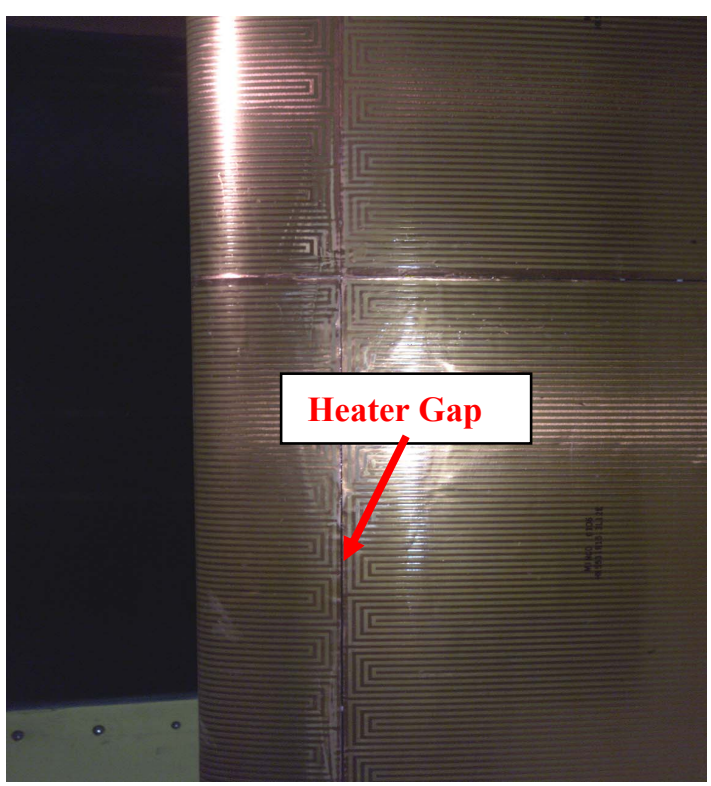

Figure 5.- Heater gap present on lower surface of airfoil during 2004 testing.

Table 5 lists the conditions which were removed from the database due to inconsistencies. The 2004 four test conditions removed from the database were conditions 16 through 19 in table 5. It should be mentioned that these conditions listed below will leave "holes" in the test grid, which will be evident in the ice feature contour plots presented in the next section.

Another consideration when interpreting ice shape feature results discussed in his report, involves the presence of large rime feathers aft of the main ice shape at the cold temperature condition. While some of the THICK calculated ice shape measurements tended to have lower standard deviation at the cold temperature, this may not necessarily imply less variation in the ice shape. This is because THICK calculations focus primarily on the main ice shape, and during some of the cold temperature runs we observed the appearance of some significant ice feathers aft of the main ice shape.

TABLE 5.-TEST CONDITIONS REMOVED FROM SENSITIVITY DATABASE

\begin{tabular}{|c|c|c|c|c|c|}
\hline Condition & $\eta_{0}$ & $P_{\text {air }},(p s i)$ & $\Delta P,(\mathrm{psi})$ & $M V D,(\mu \mathrm{m})$ & $L W C,\left(\mathrm{~g} / \mathrm{m}^{3}\right)$ \\
\hline 9 & 0.39 & 20 & 110 & 35 & .79 \\
\hline 19 & 0.39 & 25 & 160 & 36.7 & .955 \\
\hline 3 & 0.75 & 15 & 70 & 35.5 & .625 \\
\hline 16 & 0.75 & 25 & 130 & 30.6 & .861 \\
\hline 17 & 0.75 & 25 & 140 & 32.6 & .893 \\
\hline 18 & 0.75 & 25 & 150 & 34.6 & .925 \\
\hline 19 & 0.75 & 25 & 160 & 34.6 & .925 \\
\hline 29 & 0.75 & 40 & 180 & 24.4 & 1.0 \\
\hline
\end{tabular}

For some cases at the cold temperature, we observed the formation of relatively large ice feathers forming to the side of the main ice shape. This seemed to be associated with the higher MVD and $L W C$ conditions in our test matrix, but there did seem to be some randomness to it. This randomness associated with these feathers added some more variability to the overall shape of the ice tracings at the cold condition. Figure 6 illustrates a case where these feathers occurred. 


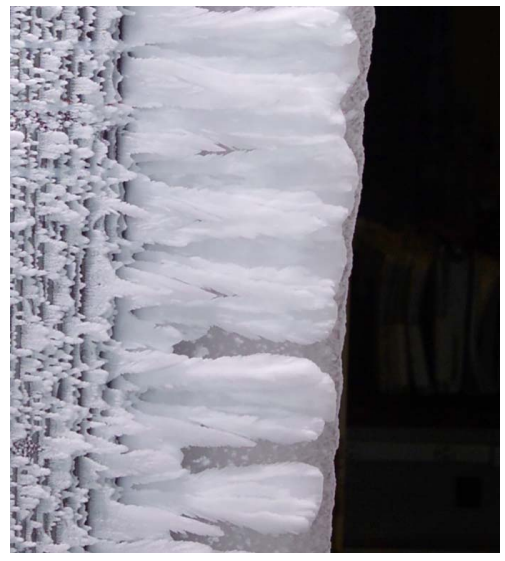

Upper surface ice feathers

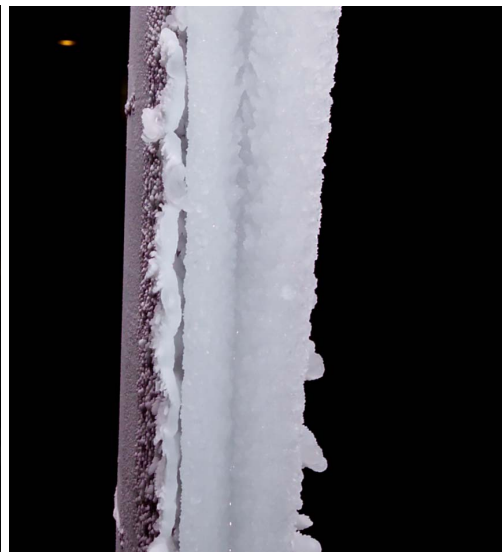

Straight-on view of accretion

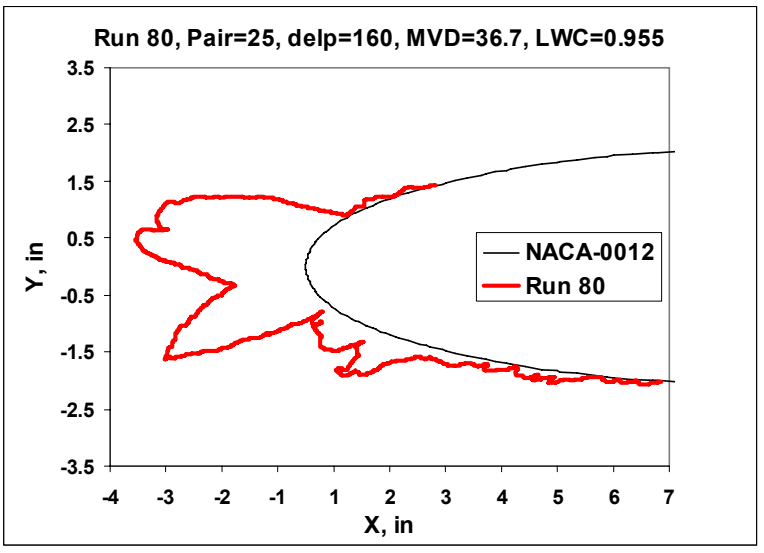

Figure 6.- Ice tracing and photos showing large feathers aft of main ice shape which was observed in some runs at $\eta_{0}=0.75$.

\section{Effect of Spray Condition Variation on Ice Shape Mass}

Ice was removed from a span-wise portion of the airfoil and then directly weighed for each test condition. The change in mass relative to the nominal condition ice shape mass was determined, and then normalized by the ice mass standard deviation using the data analysis procedure outlined previously. The change in $M V D$ and $L W C$ was also determined for each test condition relative to the nominal condition $\left(P_{\text {air nom }}=25 \mathrm{psi}, \Delta P_{\text {nom }}=120 \mathrm{psi}, L W C_{\text {nom }}=0.827 \mathrm{~g} / \mathrm{m}^{3}, M V D=28.7 \mu \mathrm{m}\right)$. These values of normalized mass change, $M V D$ change, and $L W C$ change were then input to a Matlab ${ }^{\mathrm{TM}}$ plotting routine to generate the contour plot of normalized ice mass change shown in figures 7 and 8 . The effect of varying spray conditions on ice shape mass with respect to the nominal condition is shown in figure 7 for a warm temperature $\left(T_{\text {tot }}=23{ }^{\circ} \mathrm{F}, \eta_{0}=0.39\right)$, and in figure 8 for a cold temperature $\left(T_{\text {tot }}=7.9^{\circ} \mathrm{F}, \eta_{0}=0.75\right)$.

The dark circles on the plot indicate the discrete test conditions used to generate the contour plot. The values of the normalized change in ice mass corresponding to each point on the plot were two dimensionally interpolated and colored by Matlab ${ }^{\mathrm{TM}}$. Contour lines were also added to show lines of constant normalized mass change as calculated by the interpolation routine. Each contour line has been labeled in terms of units of ice mass standard deviation. The area between the 1 and -1 contour lines represents an area where the change in ice mass was less than one standard deviation. In this area, the change was determined to be less than the normal run-to-run ice mass variation, and thus considered insignificant. Changes outside this region were considered to be significant, within the limitations of this experiment and also the accuracy of the interpolation method. 


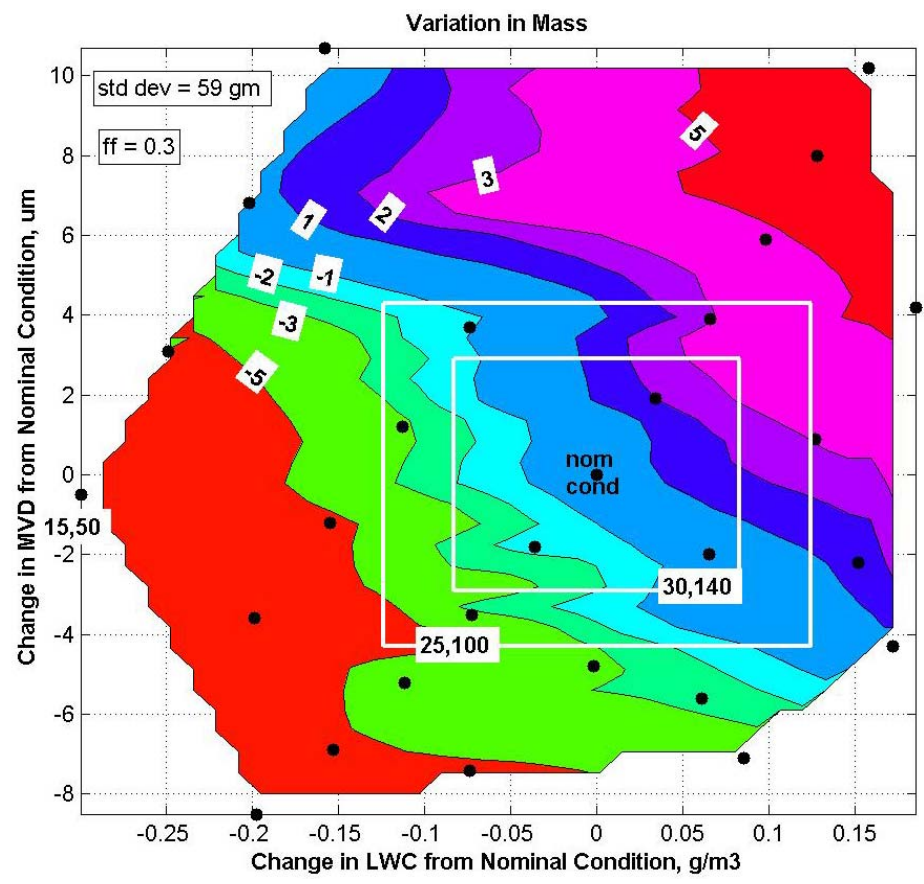

Figure 7.-Contour plot of normalized change in ice shape mass at the warm temperature $T_{\text {tot }}=23^{\circ} \mathrm{F}, T_{s}=13.5^{\circ} \mathrm{F}$, $\eta_{0}=0.39, V=200$ knots, $A O A=2.5^{\circ}, 15 \mathrm{~min}$ Spray Time. (note: contour lines labeled in units of standard deviation).

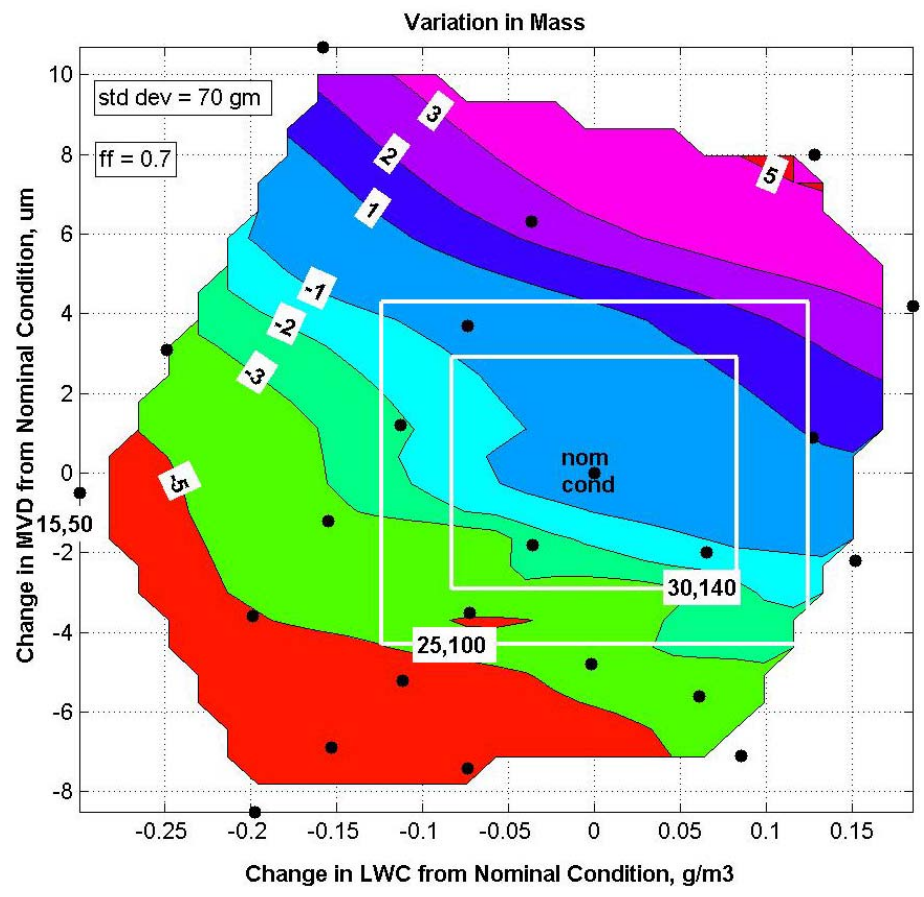

Figure 8.-Contour plot of normalized change in ice shape mass at the cold temperature $T_{\text {tot }}=7.9^{\circ} \mathrm{F}, T_{s}=-1.6^{\circ} \mathrm{F}$, $\eta_{0}=0.75, V=200$ knots, $A O A=2.5^{\circ}, 15 \mathrm{~min}$ Spray Time (note: contour lines labeled in units of standard deviation). 
Two white rectangular boxes are shown over plotted on each contour plot to represent the bound of a 10 percent variation (inner box) and 15 percent variation (outer box) about the nominal condition $\left(M V D=28.7 \mu \mathrm{m}, L W C=0.827 \mathrm{~g} / \mathrm{m}^{3}\right)$. These boxes were added to get a sense of the degree to which an ice feature (in this case normalized ice shape mass) might change due to a hypothetical 10 or 15 percent $L W C$ or $M V D$ instrumentation error in specifying the nominal condition.

Three of the test conditions have been labeled with their corresponding spray parameter values of $P_{\text {air }}$ and $\Delta P$ to allow comparison with ice shape tracings later in this report. These $\left(P_{\text {air }}, \Delta P\right)$ test points were $(15,50)$ which is an extreme condition far outside the 15 percent box, $(25,100)$ which is within the 15 percent box, and $(30,140)$ which is within the 10 percent box. This is intended to help visualize how ice tracings correspond with the contour plots at different locations within the grid of test conditions.

\section{Ice Mass Variation at $\eta_{0}=0.39$}

Figure 7 is a contour plot of normalized ice mass change plotted as a function of the change in $M V D$ and $L W C$ for the warm temperature condition $\left(T_{t o t}=23^{\circ} \mathrm{F}, T_{s}=13.5^{\circ} \mathrm{F}, \eta_{0}=0.39\right)$. Inspection of table 4 revealed that the values of normalized change in ice shape mass ranged in value from -9.1 to 7.58 standard deviations. The ice mass standard deviation for this temperature was $59 \mathrm{~g}$.

There are a number of observations which can be made about figure 7:

- The contour lines have a fairly uniform pattern, and an approximate $45^{\circ}$ orientation with respect to the plot axes.

- The change in ice mass tended to increase with increasing change in MVD and $L W C$.

- The area within the -1 to 1 contour lines is roughly centered in the 10 percent box.

- Within the 15 percent variation box, the contour lines seem to have the same approximate width.

- The maximum variation in contour line values within the 10 percent box appears to range from -3 to 3 standard deviations ( -177 to $177 \mathrm{~g})$.

- The maximum variation in contour line values within the 15 percent box appears to be -5 to \pm 5 standard deviations ( -295 to $295 \mathrm{~g}$ ).

\section{Ice Mass Variation at $\eta_{0}=0.75$}

Figure 8 is a contour plot of normalized ice shape mass change plotted as a function of the change in $M V D$ and $L W C$ for the cold temperature condition $\left(T_{t o t}=7.9^{\circ} \mathrm{F}, T_{s}=-1.6^{\circ} \mathrm{F}, \eta_{0}=0.75\right)$. Inspection of table 4 revealed that the values of normalized change in ice shape mass ranged in value from -9.65 to 5.61 standard deviations. The ice mass standard deviation for this temperature was $70 \mathrm{~g}$.

There are a number of observations which can be made about figure 8 :

- The contour lines have a fairly uniform pattern, and an approximate $45^{\circ}$ orientation with respect to the plot axes. The 1,2, and 3 contour lines appear straighter than the same lines in figure 7. This may be partly due to the lack of test points in the region at the left edge of the plot and above the central region of the plot, an the resultant action of the interpolation algorithm using one point to draw the contour line.

- Ice mass tended to increase with increasing change in $M V D$ and $L W C$.

- The area within the -1 to 1 contour lines appear to be shifted toward the upper part of the 10 and 15 percent boxes. They appear to fill a large portion of the 10 percent box.

- The maximum variation in contour line values within the 10 percent box appears to range from -3 to 1 standard deviations ( -210 to $70 \mathrm{~g}$ ).

- The maximum variation in contour line values within the 15 percent box appears to be -5 to 2 standard deviations ( -350 to $140 \mathrm{~g}$ ). 


\section{Effect of Spray Condition Variation on Upper Ice Horn Angle}

Ice tracings were acquired at each test condition, and digitized. The THICK program was then used to analyze these digitized ice tracings to determine the upper ice horn angle. Next the change in upper horn angle was determined relative to the nominal condition upper horn angle, and then normalized with respect to the upper horn angle standard deviation (using the data analysis procedure outlined previously). The change in $M V D$ and $L W C$ was also determined for each test condition relative to the nominal condition $\left(P_{\text {air nom }}=25 \mathrm{psi}, \Delta P_{\text {nom }}=120 \mathrm{psi}, L W C_{\text {nom }}=0.827 \mathrm{~g} / \mathrm{m}^{3}, M V D=28.7 \mu \mathrm{m}\right)$. These values of normalized upper horn angle change, $M V D$ change, and $L W C$ change were then input to a Matlab ${ }^{\mathrm{TM}}$ plotting routine to generate the contour plot of normalized upper ice horn angle change shown in figures 9 and 10. The effect of varying spray conditions on upper ice horn angle is shown in figure 9 for a warm temperature $\left(T_{t o t}=23^{\circ} \mathrm{F}, \eta_{0}=0.39\right)$, and in figure 10 for a cold temperature $\left(T_{\text {tot }}=7.9^{\circ} \mathrm{F}, \eta_{0}=0.75\right)$.

\section{Upper Ice Horn Variation at $\eta_{0}=0.39$}

Figure 9 is a contour plot of normalized change in upper horn angle plotted as a function of the change in $M V D$ and $L W C$ for the warm temperature condition $\left(T_{t o t}=23^{\circ} \mathrm{F}, T_{s}=13.5^{\circ} \mathrm{F}, \eta_{0}=0.39\right)$. Inspection of table 4 revealed that the values of normalized change in upper horn angle ranged in value from -8.56 to 9.75 standard deviations. The upper horn angle standard deviation for this temperature was $2.25^{\circ}$.

There are a number of observations which can be made about figure 9:

- The contour lines exhibit less uniformity than the ice mass change contour lines in figures 7 and 8.

- There is a general trend indicating an upper horn angle decrease with an increasing change in $M V D$ and $L W C$. A decreasing horn angle corresponds to the upper ice horn moving backward on the upper surface of the airfoil.

- The area within the -1 to 1 contour lines appear to be shifted slightly toward the lower part of the 10 and 15 percent boxes. These lines appear to fill a large portion of the 10 percent box.

- The maximum variation in contour line values within the 10 percent box appears to range from approximately -2 to 1 standard deviations $\left(-4.5^{\circ}\right.$ to $\left.2.25^{\circ}\right)$.

- The maximum variation in contour line values within the 15 percent box appears to be -4 to 3 standard deviations $\left(-9^{\circ}\right.$ to $\left.6.75^{\circ}\right)$.

\section{Upper Ice Horn Variation at $\eta_{0}=0.75$}

Figure 10 is a contour plot of normalized change in upper horn angle plotted as a function of the change in $M V D$ and $L W C$ for the cold temperature condition $\left(T_{t o t}=7.9^{\circ} \mathrm{F}, T_{s}=-1.6^{\circ} \mathrm{F}, \eta_{0}=0.75\right)$. Inspection of table 4 revealed that the values of normalized change in upper horn angle ranged in value from -2.44 to 8.1 standard deviations. The upper horn angle standard deviation for this temperature was $1.8^{\circ}$.

There are a number of observations which can be made about figure 10:

- The contour lines exhibit less uniformity than the ice mass change contour lines in figures 7 and 8 .

- There is a general trend indicating an upper horn angle decrease with an increasing change in $M V D$ and $L W C$. A decreasing horn angle corresponds to the upper ice horn moving backward on the upper surface of the airfoil.

- The area within the 1 contour line appears to cover a relatively large portion of the 10 percent box.

- The maximum variation in contour line values within the 10 percent box appears to range from approximately -1 to 3 standard deviations $\left(-1.8^{\circ}\right.$ to $\left.5.4^{\circ}\right)$.

- The maximum variation in contour line values within the 15 percent box appears to be -1 to 5 standard deviations $\left(-1.8^{\circ}\right.$ to $\left.9^{\circ}\right)$. 


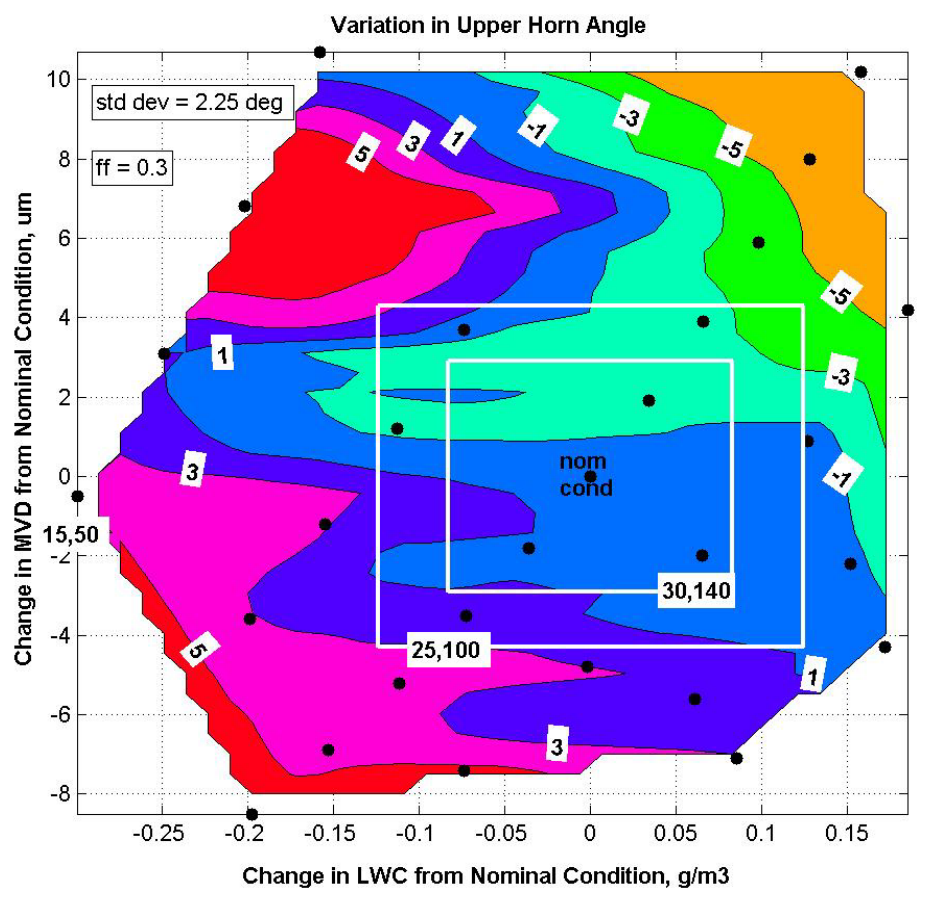

Figure 9.-Contour plot of normalized change in upper horn angle at the warm temperature $T_{\text {tot }}=23^{\circ} \mathrm{F}$, $T_{s}=13.5^{\circ} \mathrm{F}, \eta_{0}=0.39, V=200$ knots, $A O A=2.5^{\circ}$, 15 min Spray Time. (note: contour lines labeled in units of standard deviation).

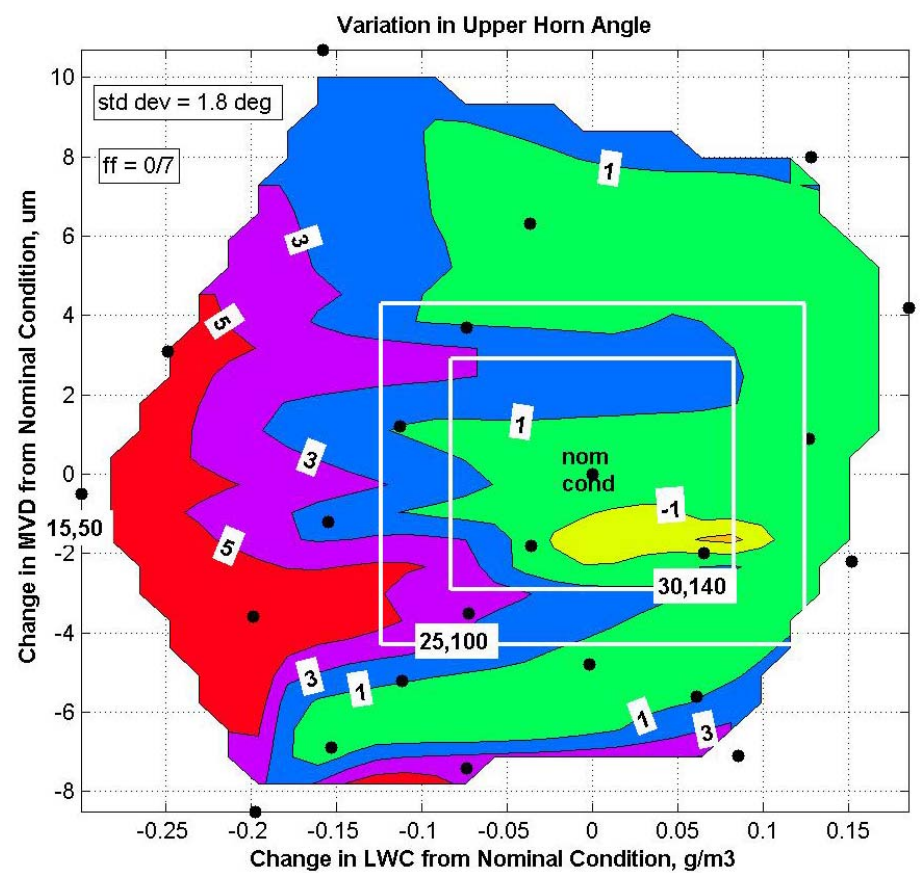

Figure 10.-Contour plot of normalized change in upper horn angle at the cold temperature $T_{\text {tot }}=7.9^{\circ} \mathrm{F}$, $T_{s}=-1.6^{\circ} \mathrm{F}, \eta_{0}=0.75, V=200$ knots, $A O A=2.5^{\circ}$, 15 min Spray Time. (note: contour lines labeled in units of standard deviation). 


\section{E. Effect of Spray Condition Variation on Lower Ice Horn Angle}

Ice tracings were acquired at each test condition, and digitized. The THICK program was then used to analyze these digitized ice tracings to determine the lower ice horn angle. Next the change in lower horn angle was determined relative to the nominal condition lower horn angle, and then normalized with respect to the lower horn angle standard deviation (using the data analysis procedure outlined previously). The change in $M V D$ and $L W C$ was also determined for each test condition relative to the nominal condition $\left(P_{\text {air nom }}=25 \mathrm{psi}, \Delta P_{\text {nom }}=120 \mathrm{psi}, L W C_{\text {nom }}=0.827 \mathrm{~g} / \mathrm{m}^{3}, M V D=28.7 \mu \mathrm{m}\right)$. These values of normalized lower horn angle change, $M V D$ change, and $L W C$ change were then input to a Matlab ${ }^{\mathrm{TM}}$ plotting routine to generate the contour plot of normalized lower ice horn angle change shown in figures 11 and 12. The effect of varying spray conditions on lower ice horn angle is shown in figure 11 for a warm temperature $\left(T_{t o t}=23^{\circ} \mathrm{F}, \eta_{0}=0.39\right)$, and in figure 12 for a cold temperature $\left(T_{\text {tot }}=7.9^{\circ} \mathrm{F}\right.$, $\left.\eta_{0}=0.75\right)$.

\section{Lower Ice Horn Angle Variation at $\eta_{0}=0.39$}

Figure 11 is a contour plot of normalized change in lower horn angle plotted as a function of the change in $M V D$ and $L W C$ for the warm temperature condition $\left(T_{t o t}=23^{\circ} \mathrm{F}, T_{s}=13.5^{\circ} \mathrm{F}, \eta_{0}=0.39\right)$. Inspection of table 4 revealed that the values of normalized change in lower horn angle ranged in value from -8.23 to 2.79 standard deviations. The lower horn angle standard deviation for this temperature was $5.2^{\circ}$.

There are a number of observations which can be made about figure 11:

- The contour lines exhibit less uniformity than the ice mass change contour lines in figures 7 and 8.

- There is a general trend indicating a lower horn angle increase with an increasing change in $M V D$ and $L W C$. An increasing lower horn angle corresponds to the lower ice horn moving backward on the lower surface of the airfoil. It is just the opposite from the upper horn angle trend.

- The area within the -1 to 1 contour lines appears to almost entirely fill the 10 percent box.

- The 15 percent box is almost entirely filled by the -2 to 2 contour lines.

- The maximum variation in contour line values within the 10 percent box appears to range from approximately -1 to 2 standard deviations $\left(-5.2^{\circ}\right.$ to $\left.10.4^{\circ}\right)$.

- The maximum variation in contour line values within the 15 percent box appears to be -3 to 2 standard deviations $\left(-15.6^{\circ}\right.$ to $\left.10.4^{\circ}\right)$.

\section{Lower Ice Horn Angle Variation at $\eta_{0}=0.75$}

Figure 12 is a contour plot of normalized change in lower horn angle plotted as a function of the change in $M V D$ and $L W C$ for the cold temperature condition $\left(T_{t o t}=7.9^{\circ} \mathrm{F}, T_{s}=-1.6^{\circ} \mathrm{F}, \eta_{0}=0.75\right)$. Inspection of table 4 revealed that the values of normalized change in lower horn angle ranged in value from -7.27 to 15.9 standard deviations. The lower horn angle standard deviation for this temperature was $1.1^{\circ}$.

There are a number of observations which can be made about figure 12:

- The contour lines exhibit less uniformity than the ice mass change contour lines in figures 7 and 8 . There appears to be less of a clearly defined trend for changes in lower horn angle at this temperature, although it looks as if the contour line values might generally increase as you increase $M V D$ and $L W C$.

- The area within the 1 contour line appears to cover the lower half of the 10 and 15 percent boxes, with the area contained within the 3 and 5 contour lines covering the upper half of these boxes. The area within the 5 contour lines contains values up to about 7.5 standard deviations.

- The maximum variation in contour line values within the 10 percent box appears to range from approximately -3 to 5 standard deviations $\left(-3.3^{\circ}\right.$ to $\left.5.5^{\circ}\right)$.

- The maximum variation in contour line values within the 15 percent box appears to be -3 to 5 standard deviations $\left(-3.3^{\circ}\right.$ to $\left.5.5^{\circ}\right)$. 


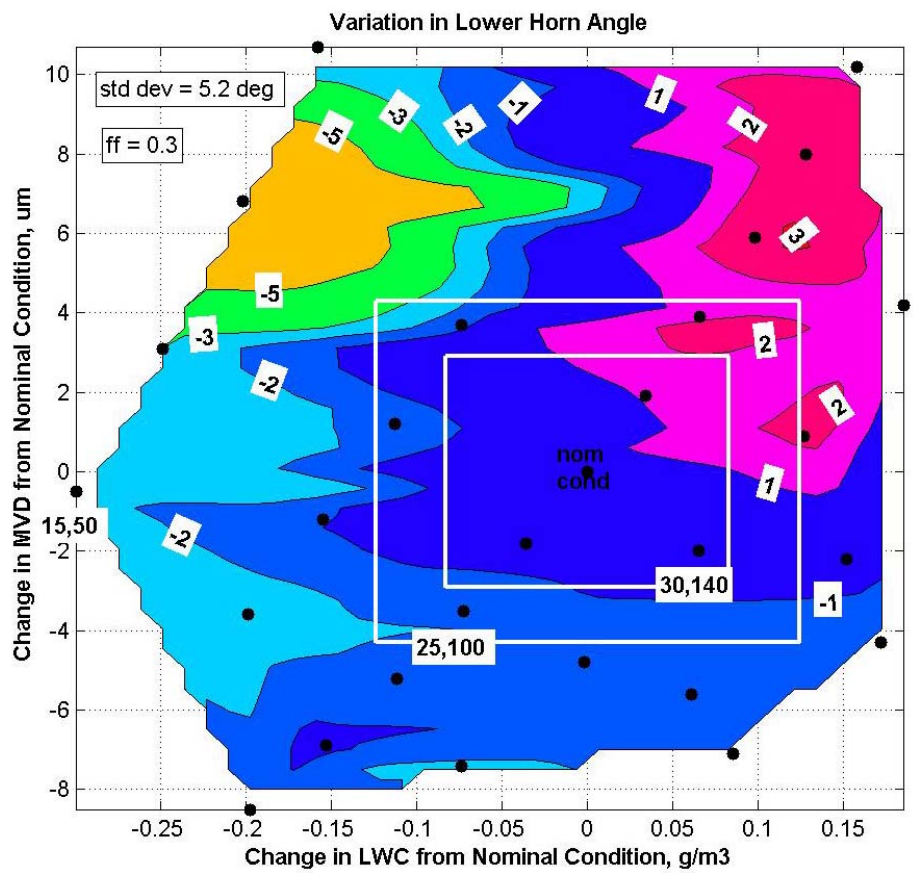

Figure 11.-Contour plot of normalized change in lower horn angle at the warm temperature $T_{\text {tot }}=23^{\circ} \mathrm{F}$, $T_{s}=13.5^{\circ} \mathrm{F}, \eta_{0}=0.39, V=200$ knots, $A O A=2.5^{\circ}$, 15 min Spray Time. (note: contour lines labeled in units of standard deviation).

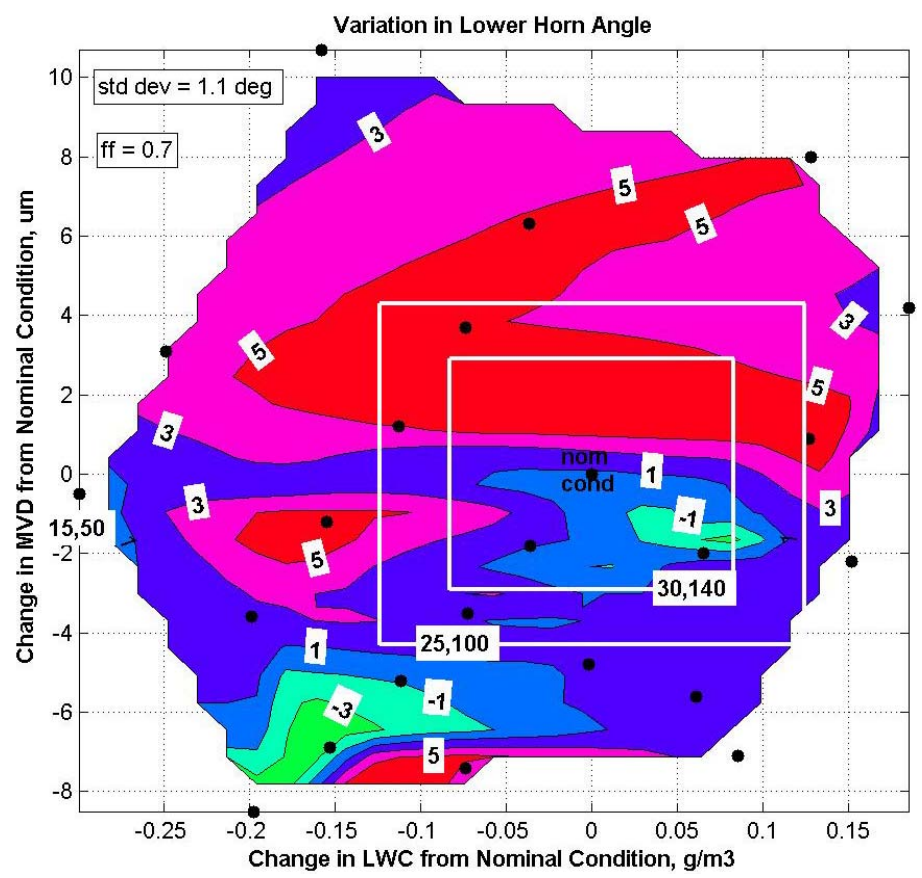

Figure 12.-Contour plot of normalized change in lower horn angle at the cold temperature $T_{\text {tot }}=7.9^{\circ} \mathrm{F}$, $T_{s}=-1.6^{\circ} \mathrm{F}, \eta_{0}=0.75, V=200$ knots, $A O A=2.5^{\circ}$, 15 min Spray Time. (note: contour lines labeled in units of standard deviation). 


\section{F. Effect of Spray Condition Variation on Upper Ice Horn Thickness}

Ice tracings were acquired at each test condition, and digitized. The THICK program was then used to analyze these digitized ice tracings to determine the upper ice horn thickness. Next the change in upper horn thickness was determined relative to the nominal condition upper horn thickness, and then normalized with respect to the upper horn thickness standard deviation (using the data analysis procedure outlined previously). The change in $M V D$ and $L W C$ was also determined for each test condition relative to the nominal condition $\left(P_{\text {air nom }}=25 \mathrm{psi}, \Delta P_{\text {nom }}=120 \mathrm{psi}, L W C_{\text {nom }}=0.827 \mathrm{~g} / \mathrm{m}^{3}, M V D=28.7 \mu \mathrm{m}\right)$. These values of normalized upper horn thickness change, $M V D$ change, and $L W C$ change were then input to a Matlab $^{\mathrm{TM}}$ plotting routine to generate the contour plot of normalized upper ice horn thickness change shown in figures 13 and 14. The effect of varying spray conditions on upper ice horn thickness is shown in figure 13 for a warm temperature $\left(T_{\text {tot }}=23^{\circ} \mathrm{F}, \eta_{0}=0.39\right)$, and in figure 14 for a cold temperature $\left(T_{\text {tot }}=\right.$ $\left.7.9^{\circ} \mathrm{F}, \eta_{0}=0.75\right)$.

\section{Upper Ice Horn Thickness Variation at $\eta_{0}=0.39$}

Figure 13 is a contour plot of normalized change in upper horn thickness plotted as a function of the change in $M V D$ and $L W C$ for the warm temperature condition $\left(T_{t o t}=23{ }^{\circ} \mathrm{F}, T_{s}=13.5^{\circ} \mathrm{F}, \eta_{0}=0.39\right)$.

Inspection of table 4 revealed that the values of normalized change in upper horn thickness ranged in value from -4.75 to 1.48 standard deviations. The upper horn thickness standard deviation for this temperature was 0.15 in.

There are a number of observations which can be made about figure 13:

- The contour lines exhibit less uniformity than the ice mass change contour lines in figures 7 and 8.

- There is a general trend indicating an increase in upper ice horn thickness with an increasing change in $M V D$ and $L W C$, but the magnitude of this change in terms of ice thickness standard deviation appears to be rather small.

- A significant portion of the contour plot is encompassed by -1 to 1 contour lines. This level of change in this area is on the order of run-to-run ice shape repeatability.

- The area within the -1 to 0.5 contour lines appear to almost entirely fill the 10 percent box.

- A large area of the 15 percent box is almost completely filled by the -2 to 0.5 contour line.

- The 15 percent box is almost entirely filled by the area within the -2 to 2 contour lines.

- The maximum variation in contour lines within the 10 percent box appears to range from approximately -2 to 0.5 standard deviations ( -0.30 to 0.075 in.).

- The maximum variation in contour line values within the 15 percent box appears to be about the same as the 10 percent box.

\section{Upper Ice Horn Thickness Variation at $\eta_{0}=0.75$}

Figure 14 is a contour plot of normalized change in upper horn thickness plotted as a function of the change in $M V D$ and $L W C$ for the cold temperature condition $\left(T_{\text {tot }}=7.9^{\circ} \mathrm{F}, T_{s}=-1.6^{\circ} \mathrm{F}, \eta_{0}=0.75\right)$. Inspection of table 4 revealed that the values of normalized change in upper horn thickness ranged in value from -10.73 to 4.35 standard deviations. The upper horn thickness standard deviation for this temperature was 0.11 in.

There are a number of observations which can be made about figure 14:

- The contour lines appear to exhibit more uniformity, and look more like the contour line pattern in the ice shape mass variation plots in figures 7 and 8 .

- There is a general trend indicating an increase in upper ice horn thickness with an increasing change in $M V D$ and $L W C$. The area within the -1 to 1 contour lines appears to be shifted somewhat toward the upper half of the 10 percent box.

- The maximum variation in contour lines within the 10 percent box appears to range from approximately -5 to 2 standard deviations ( -0.55 to 0.22 in.)

- The maximum variation in contour line values within the 15 percent box appears to range from approximately -8 to 4 standard deviations ( -0.88 to 0.44 in.). 


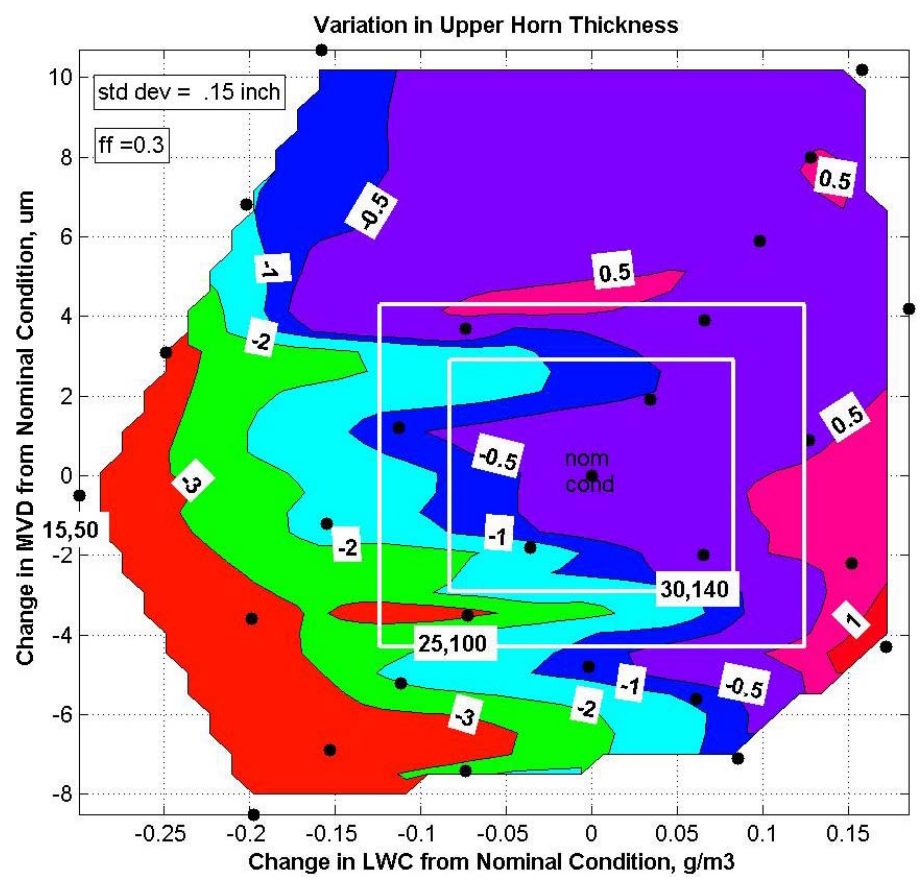

Figure 13.-Contour plot of normalized change in upper horn thickness at the warm temperature $T_{\text {tot }}=23^{\circ} \mathrm{F}$, $T_{s}=13.5^{\circ} \mathrm{F}, \eta_{0}=0.39, V=200$ knots, $A O A=2.5^{\circ}$, 15 min Spray Time. (note: contour lines labeled in units of standard deviation).

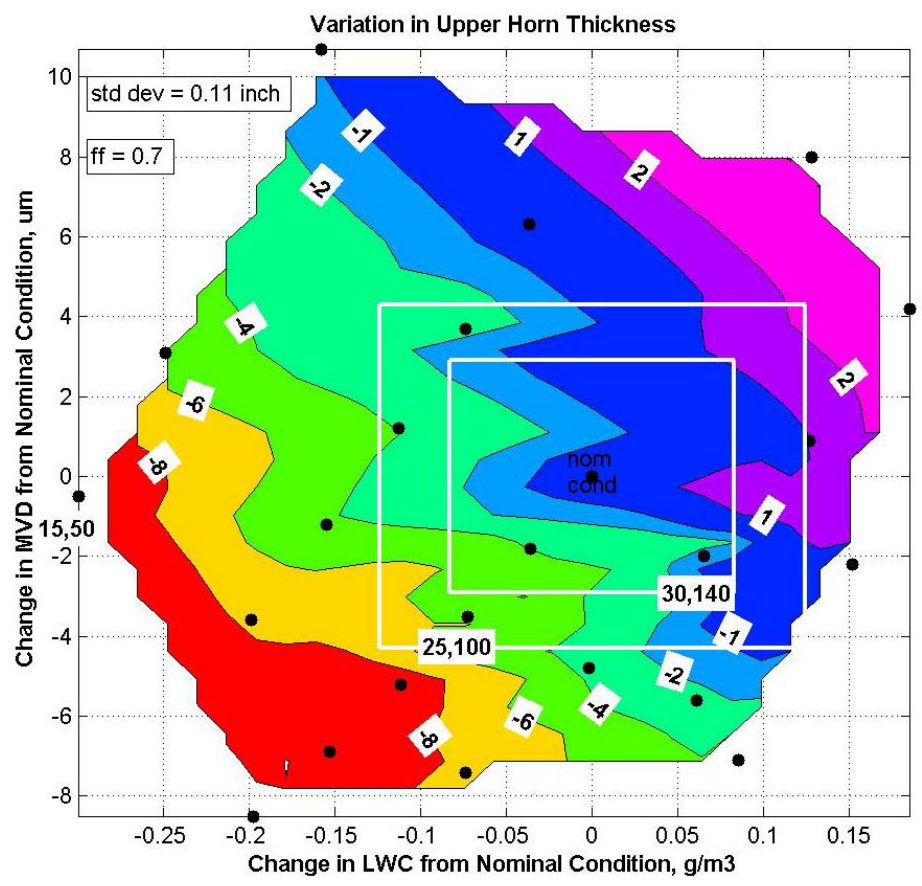

Figure 14.-Contour plot of normalized change in upper horn thickness at the cold temperature $T_{\text {tot }}=7.9^{\circ} \mathrm{F}$, $T_{s}=-1.6^{\circ} \mathrm{F}, \eta_{0}=0.75, V=200$ knots, $A O A=2.5^{\circ}$, 15 min Spray Time. (note: contour lines labeled in units of standard deviation). 


\section{G. Effect of Spray Variation on Lower Ice Horn Thickness}

Ice tracings were acquired at each test condition, and digitized. The THICK program was then used to analyze these digitized ice tracings to determine the lower ice horn thickness. Next the change in lower horn thickness was determined relative to the nominal condition lower horn thickness, and then normalized with respect to the lower horn thickness standard deviation (using the data analysis procedure outlined previously). The change in $M V D$ and $L W C$ was also determined for each test condition relative to the nominal condition $\left(P_{\text {air nom }}=25 \mathrm{psi}, \Delta P_{\text {nom }}=120 \mathrm{psi}, L W C_{\text {nom }}=0.827 \mathrm{~g} / \mathrm{m}^{3}, M V D=28.7 \mu \mathrm{m}\right)$. These values of normalized lower horn thickness change, $M V D$ change, and $L W C$ change were then input to a $\mathrm{Matlab}^{\mathrm{TM}}$ plotting routine to generate the contour plot of normalized lower ice horn thickness change shown in figures 15 and 16. The effect of varying spray conditions on lower ice horn thickness is shown in figure 15 for a warm temperature $\left(T_{\text {tot }}=23^{\circ} \mathrm{F}, \eta_{0}=0.39\right)$, and in figure 16 for a cold temperature $\left(T_{\text {tot }}=7.9^{\circ} \mathrm{F}, \eta_{0}=0.75\right)$.

\section{Lower Ice Horn Thickness Variation at $\eta_{0}=0.39$}

Figure 15 is a contour plot of normalized change in lower horn thickness plotted as a function of the change in $M V D$ and $L W C$ for the warm temperature condition $\left(T_{t o t}=23^{\circ} \mathrm{F}, T_{s}=13.5^{\circ} \mathrm{F}, \eta_{0}=0.39\right)$.

Inspection of table 4 revealed that the values of normalized change in lower horn thickness ranged in value from -5.22 to 2.0 standard deviations. The lower horn thickness standard deviation for this temperature was 0.115 in.

There are a number of observations which can be made about figure 15:

- The contour lines tend to exhibit a degree of uniformity, although not as much as the ice mass change contour lines in figures 7 and 8.

- There is a general trend indicating an increase in lower ice horn thickness with an increasing change in $M V D$ and $L W C$.

- A significant portion of the contour plot is encompassed by the area within the -1 to 1 contour lines. This level of change in this area is on the order of run-to-run ice shape repeatability.

- The area within the -1 to 0.5 contour lines appear to almost entirely fill the 10 percent box.

- About half of the right side of the 15 percent box is almost completely filled by the -2 to 0.5 contour line.

- The area within the -2 to 1 contour lines almost completely fills the 15 percent box.

- The maximum variation in contour lines within the 10 percent box appears to range from approximately -2 to 1 standard deviations ( -0.23 to 0.115 in).

- The maximum variation in contour line values within the 15 percent box appears to range from approximately -3 to 1 standard deviations ( -0.345 to 0.115 in).

\section{Lower Ice Horn Thickness Variation at $\eta_{0}=0.75$}

Figure 16 is a contour plot of normalized change in lower horn thickness plotted as a function of the change in $M V D$ and $L W C$ for the cold temperature condition $\left(T_{t o t}=7.9^{\circ} \mathrm{F}, T_{s}=-1.6^{\circ} \mathrm{F}, \eta_{0}=0.75\right)$. Inspection of table 4 revealed that the values of normalized change in lower horn thickness ranged in value from -10.73 to 4.35 standard deviations. The lower horn thickness standard deviation for this temperature was 0.07 in.

There are a number of observations which can be made about figure 16:

- The contour lines appear to exhibit more uniformity, and look more like the contour line pattern in the ice shape mass variation plots in figures 7 and 8.

- There is a general trend indicating an increase in lower ice horn thickness with an increasing change in $M V D$ and $L W C$. The area within the -1 to 1 contour lines appears to be shifted somewhat toward the upper half of the 10 percent box.

- The maximum variation in contour lines within the 10 percent box appears to range from approximately -6 to 2 standard deviations ( -0.42 to 0.14 in).

- The maximum variation in contour line values within the 15 percent box appears to range from approximately -8 to 4 standard deviations ( -0.56 to 0.28 in). 


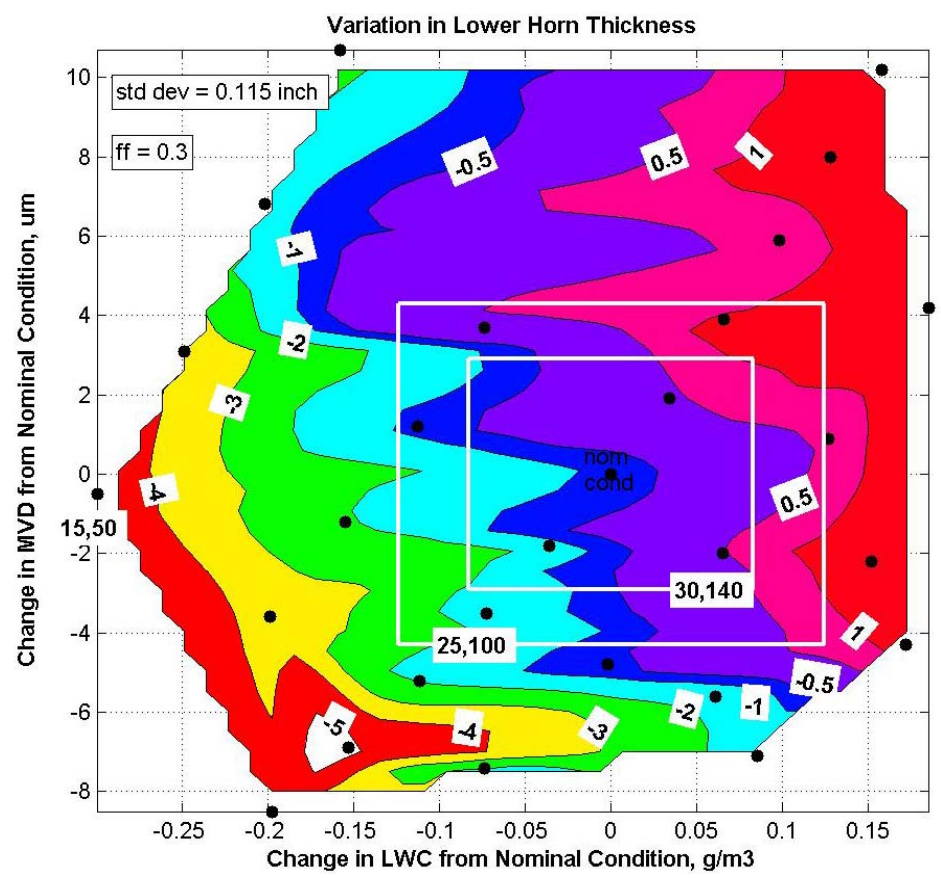

Figure 15.-Contour plot of normalized change in lower horn thickness at the warm temperature $T_{\text {tot }}=23^{\circ} \mathrm{F}$, $T_{s}=13.5^{\circ} \mathrm{F}, \eta_{0}=0.39, V=200$ knots, $A O A=2.5^{\circ}$, $15 \mathrm{~min}$ Spray Time. (note: contour lines labeled in units of standard deviation).

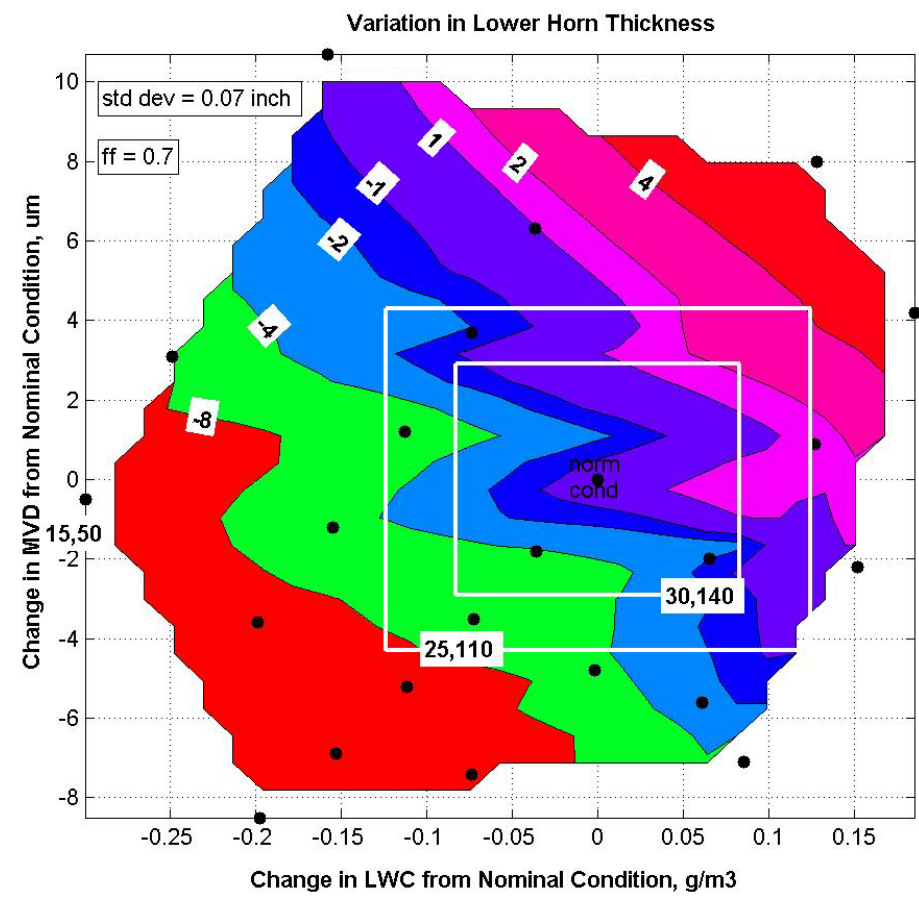

Figure 16.-Contour plot of normalized change in lower horn thickness at the cold temperature $T_{\text {tot }}=7.9^{\circ} \mathrm{F}$, $T_{s}=-1.6^{\circ} \mathrm{F}, \eta_{0}=0.75, V=200$ knots, $A O A=2.5^{\circ}$, 15 min Spray Time. (note: contour lines labeled in units of standard deviation). 


\section{H. Selected Ice Shape Comparisons}

The contour plots presented in the previous sections, provide a graphical illustration of the general trends in ice feature change about the nominal condition. As a check on the validity of these contour plots, it was decided to select three test conditions and qualitatively compare their ice tracings with the ice shape feature trends shown in the contour plots. The three conditions selected were:

- $P_{\text {air }}=30$ psi, $\Delta P=140$ psi, $M V D=26.7 \mu \mathrm{m}$, and $L W C=0.892 \mathrm{~g} / \mathrm{m}^{3}$ (within 10 percent box)

- $P_{\text {air }}=25 \mathrm{psi}, \Delta P=100 \mathrm{psi}, M V D=25.2 \mu \mathrm{m}$, and $L W C=0.754 \mathrm{~g} / \mathrm{m}^{3}$ (outside 10 percent box, but within 15 percent box)

- $P_{\text {air }}=15 \mathrm{psi}, \Delta P=50 \mathrm{psi}, M V D=28.2 \mu \mathrm{m}$, and $L W C=0.527 \mathrm{~g} / \mathrm{m}^{3}$ (outside 15 percent box)

A graphical label was used to label to identify these test points on each ice feature contour plot in figures 7 through 16.

\section{Within the 10 percent box}

The first test condition to be discussed corresponds to the test condition with a spray bar setting of $P_{\text {air }}=30 \mathrm{psi}, \Delta P=140 \mathrm{psi}, M V D=26.7 \mu \mathrm{m}$, and $L W C=0.892 \mathrm{~g} / \mathrm{m}^{3}$. It is contained within the 10 percent box and is fairly close to the nominal condition. The ice tracings associated with the warm (run 56) and cold (run 70) test condition are shown in figure 17(a) and (b), respectively. To aid in making a better qualitative assessment about the significance of their ice features, they have been over plotted on the nominal condition ice tracings to see if the ice shape falls within the variability of the nominal condition ice shape tracings.

Review of the ice feature contour plots in figures 7 through 16 indicates that this test point was typically within contour lines having values of -1 and 1 . This would suggest that it is within the normal run-to-run variability inherent in the spray condition, and that one would not be able to discern a significant change in the ice shape features associated with this test condition.

That trend is confirmed by both ice tracings which agree very closely with the nominal condition ice tracings they are compared with in figure 17(a) and (b). The upper horn from run 56 in figure 17(a) extends a little bit outside the envelope of the nominal condition tracings, but the rest of the run 56 ice shape falls within the repeatability envelope of the 5 nominal condition ice tracings also plotted in figure $17(\mathrm{a})$.

\section{Outside the 10 percent box but within the 15 percent box}

The second test condition to be compared with the contour plot ice features corresponded to a condition of $P_{\text {air }}=25 \mathrm{psi}, \Delta P=100 \mathrm{psi}, M V D=25.2 \mu \mathrm{m}$, and $L W C=0.754 \mathrm{~g} / \mathrm{m}^{3}$. It is contained within the 15 percent box and is located between the 10 and 15 percent variation lines. The ice tracings associated with the warm (run 29) and cold (run 33) test condition are shown in figure 18(a) and (b), respectively. To aid in making a better qualitative assessment about the significance of their ice features, they have been over plotted on the nominal condition ice tracings to see if the ice shape falls within the variability of the nominal condition ice shape tracings.

A review of the various ice feature contour plots in figures 7 through 16 at this test condition indicated the following ice feature changes associated with this condition:

- Slight increase in upper horn angle of approximately $5^{\circ}$

- Upper horn thickness decrease: of approximately $0.5 \mathrm{in}$.

- Slight decrease in lower horn angle of approximately $5^{\circ}$

- Lower horn thickness decrease of approximately 0.2 to 0.6 in.

Generally speaking these trends agree well with the observed changes in the main ice shape for run 29 (warm temperature) and run 33 (cold temperature) as shown in figure 18. 
Run 56: $\quad P a i r=30$, de $P=140, M V D=26.7, L W C=0.892$

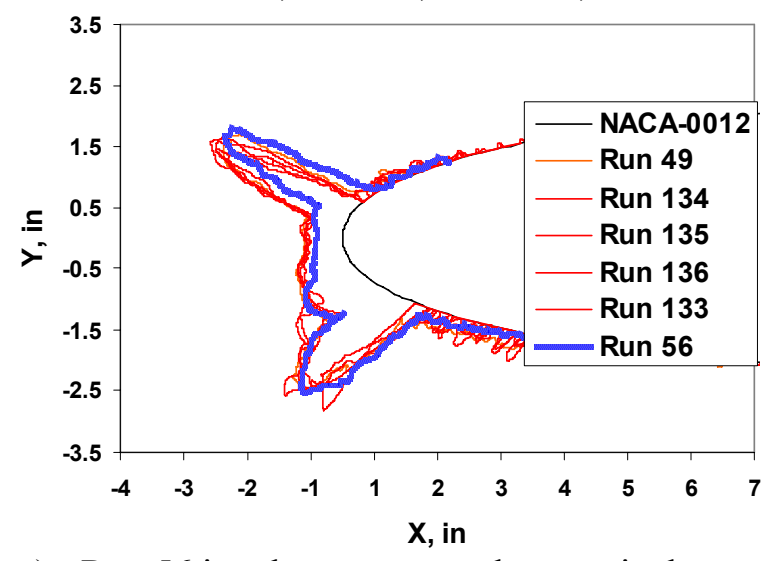

a) Run 56 ice shape compared to nominal conditions at the warm temperature $\left(\eta_{0}=0.39\right)$.

Run 70: Pair=30, delP=140, MVD=26.7, LWC=0.892

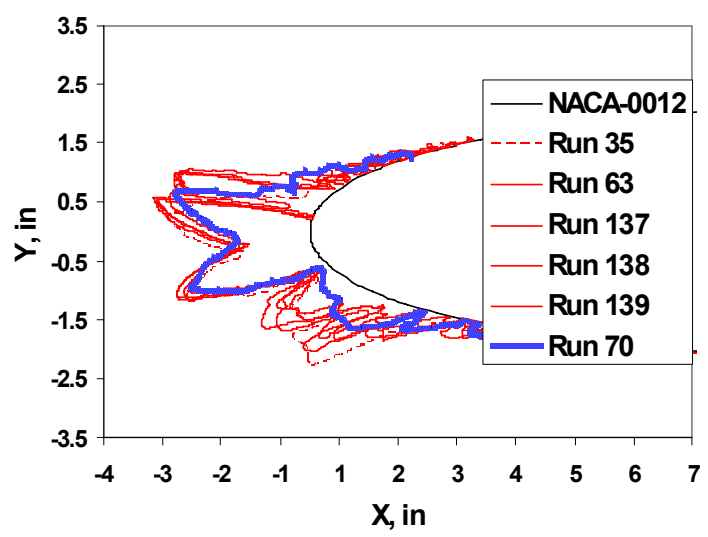

b) Run 70 ice shape compared to nominal conditions at the cold temperature $\left(\eta_{0}=0.75\right)$.

Figure 17.- Variant condition ice shape compared to nominal condition ice shapes for $\left(\eta_{0}=0.39\right)$ and $\left(\eta_{0}=0.79\right)$. This spray condition was within the \pm 10 percent contour plot "box". Nominal condition corresponded to $\left(P_{\text {air nom }}=25 \mathrm{psi}, \Delta P_{\text {nom }}=120 \mathrm{psi}\right.$, $\left.L W C_{\text {nom }}=0.827 \mathrm{~g} / \mathrm{m}^{3}\right)$. 
Run 29: $P$ air=25, deIP=100, $M V D=25.2, L W C=0.754$

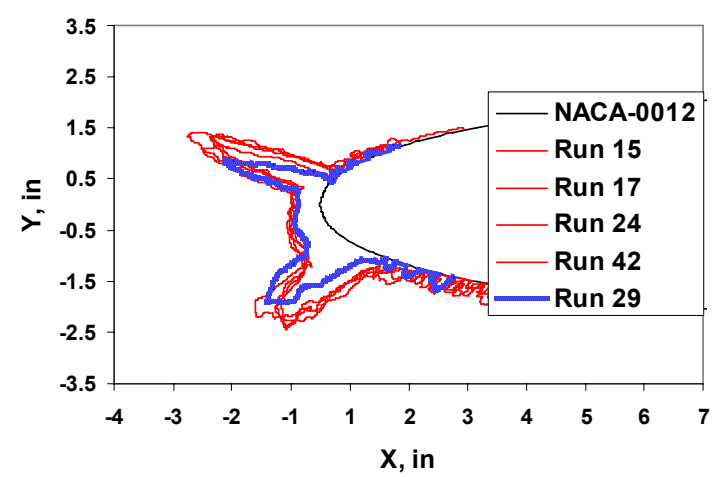

a) Run 29 ice shape tracing comparison $\left(\eta_{0}=0.39\right)$.

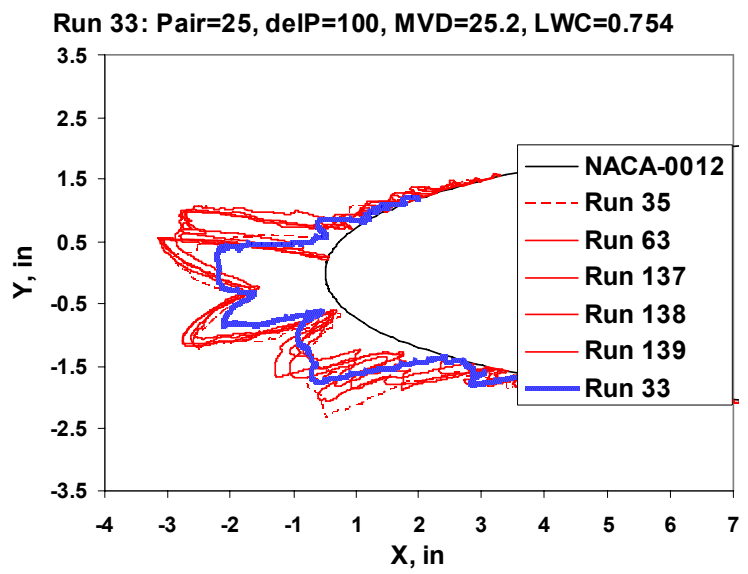

b) Run 33 ice shape tracing comparison $\left(\eta_{0}=0.75\right)$.

Figure 18.- Variant condition ice shape compared to nominal condition ice shapes for $\left(\eta_{0}=0.39\right)$ and $\left(\eta_{0}=0.79\right)$. This spray condition was outside the 10 percent box, but within the \pm 15 percent contour plot "box". Nominal condition corresponded to $\left(P_{\text {air nom }}=25 \mathrm{psi}, \Delta P_{\text {nom }}=120 \mathrm{psi}, L W C_{\text {nom }}=\right.$ $\left.0.827 \mathrm{~g} / \mathrm{m}^{3}\right)$.

\section{Outside the 15 percent box}

The last test condition to be compared with the contour plot ice features corresponded to a condition of $P_{\text {air }}=15 \mathrm{psi}, \Delta P=50 \mathrm{psi}, M V D=28.2 \mu \mathrm{m}$, and $L W C=0.527 \mathrm{~g} / \mathrm{m}^{3}$. It represents a condition well outside the 15 percent box, and was included to look at a more extreme change. The ice tracings associated with the warm (run 83) and cold (run 87) test condition are shown in figure 19(a) and (b), respectively. To aid in making a better qualitative assessment about the significance of their ice features, they have been over plotted on the nominal condition ice tracings to see if the ice shape falls within the variability of the nominal condition ice shape tracings.

A review of the various ice feature contour plots in figures 7 through 16 at this test condition indicates that this condition was at the extreme left side of the contour plot area. Despite the fact that no contour lines could be calculated for it, it serves as an example of a more extreme example of spray condition variation included in this sensitivity test matrix. 
The $M V D$ for this case was approximately the same as the nominal condition, thus any changes in this plot would be due to a change in $L W C$ of approximately $0.3 \mathrm{~g} / \mathrm{m}^{3}$. Typically a decrease in $L W C$ causes the icing horn thickness to decrease, and the icing horns tend to rotate in toward the stagnation line. This general trend can be observed in figures 19(a) and (b). Since this test condition represented a more extreme change in spray conditions, compared to the two previous test conditions which were evaluated in figures 17 and 18, the changes in ice shape should be greater in magnitude. This is the case for the ice tracings in figure 19.

Run 83: Pair=15, delP=50, MVD=28.2, $L W C=0.527$

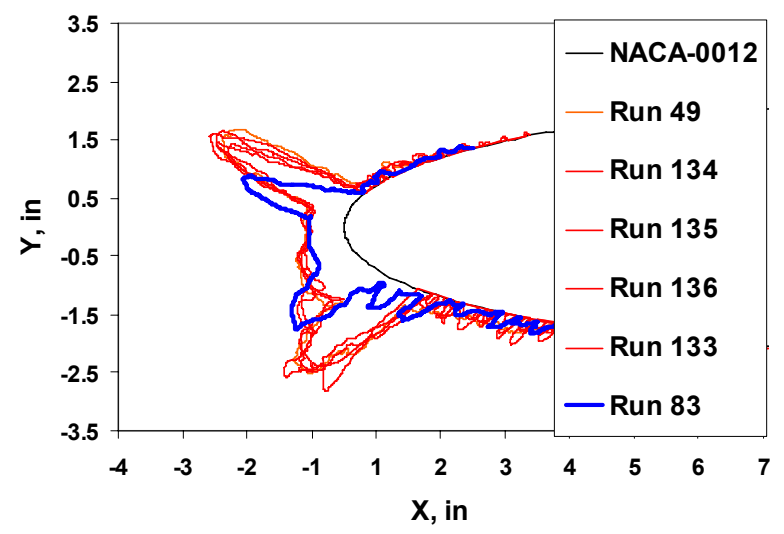

a) Run 83 ice shape tracing compared to nominal condition at $\left(\eta_{0}=0.39\right)$.

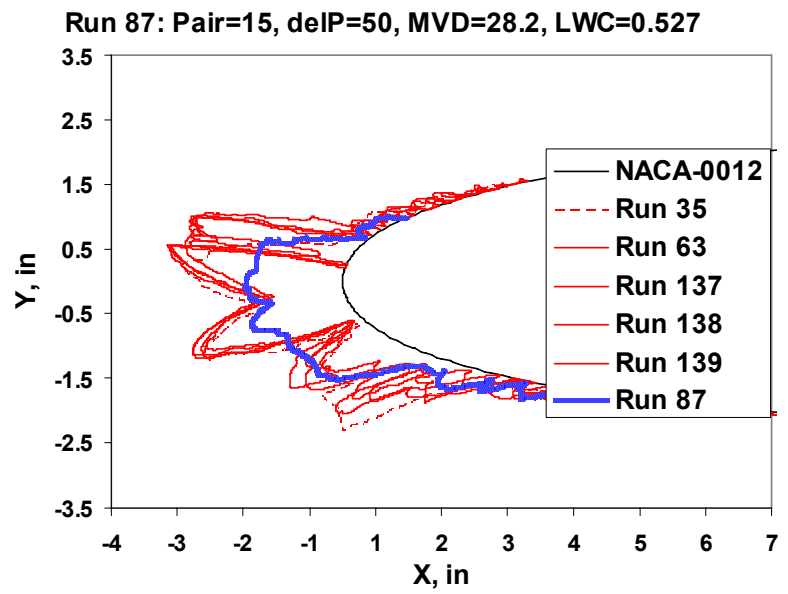

b) Run 87 ice shape tracing compared to nominal condition at $\left(\eta_{0}=0.75\right)$.

Figure 19.--Extreme variant condition ice shape compared to nominal condition ice tracings for $\left(\eta_{0}=0.39\right)$ and $\left(\eta_{0}=0.79\right)$. This spray condition was outside the \pm 15 percent contour plot "box" Nominal condition corresponded to $\left(P_{\text {air nom }}=25 \mathrm{psi}, \Delta P_{\text {nom }}=\right.$ $\left.120 \mathrm{psi}, L W C_{\text {nom }}=0.827 \mathrm{~g} / \mathrm{m}^{3}\right)$. 


\section{Summary of Results}

One of the main objectives of this study was to develop a better understanding of what level of icing spray variations are required to cause a specific level of variation $n$ the ice shape. If we could begin to establish a link between a level of spray variation and it's resultant effect on ice shape feature changes, we would have taken an important step in determining "how good" our instrumentation and simulation methods need to be. If aerodynamic effects could then be correlated with the ice feature changes, these aerodynamic effects could then be used as additional criteria in defining acceptable levels of ice feature change, which in turn could help us determine how good our instrumentation or simulation capability needs to be.

This use of the 10 and 15 percent boxes on the contour plots was a preliminary attempt to determine what levels of icing feature change would correlate with a 10 or 15 percent variation in $M V D$ and $L W C$, relative to a nominal $M V D$ of $28.7 \mu \mathrm{m}$, and a nominal $L W C$ of $0.827 \mathrm{~g} / \mathrm{m}^{3}$. Table 6 lists the value of ice feature change associated with a 15 percent variation in $L W C$, which would correspond to a change of $0.124 \mathrm{~g} / \mathrm{m}^{3}$. The values in the table were obtained from the contour plots in figures 7 to 16 , by moving to the right (increase) or left (decrease) with respect to the nominal condition, and then determining the value of the contour line which intersected the 15 percent variation line. In cases where the 15 percent box did not intersect a contour line, judgment was used to estimate what the intersecting contour line would have been.

TABLE 6.-CONTOUR PLOT ICE FEATURE CHANGES FOR 15 PERCENT CHANGE IN LWC

\begin{tabular}{|c|c|c|c|c|c|c|c|c|c|c|c|}
\hline \multirow{2}{*}{$\eta_{0}$} & \multirow{2}{*}{ Change } & \multicolumn{2}{|c|}{$\begin{array}{l}\text { Ice Shape } \\
\text { Mass }\end{array}$} & \multicolumn{2}{|c|}{$\begin{array}{c}\text { Upper Horn } \\
\text { Angle }\end{array}$} & \multicolumn{2}{|c|}{$\begin{array}{l}\text { Lower Horn } \\
\text { Angle }\end{array}$} & \multicolumn{2}{|c|}{$\begin{array}{l}\text { Upper Horn } \\
\text { Thickness }\end{array}$} & \multicolumn{2}{|c|}{$\begin{array}{l}\text { Lower Horn } \\
\text { Thickness }\end{array}$} \\
\hline & & $\begin{array}{l}\text { std } \\
\text { dev }\end{array}$ & gm & $\begin{array}{l}\text { std } \\
\text { dev }\end{array}$ & deg & $\begin{array}{l}\text { std } \\
\text { dev }\end{array}$ & deg & $\begin{array}{l}\text { std } \\
\text { dev }\end{array}$ & inch & $\begin{array}{l}\text { std } \\
\text { dev }\end{array}$ & inch \\
\hline & 1 std dev & & 59 & & 2.25 & & 5.2 & & 0.15 & & 0.115 \\
\hline \multirow{2}{*}{0.39} & $\begin{array}{c}15 \% \\
\text { increase } \\
\text { in LWC }\end{array}$ & 2.5 & 148 & -0.5 & -1.1 & 1.5 & 7.5 & 0.5 & 0.08 & 0.8 & 0.09 \\
\hline & $\begin{array}{c}15 \% \\
\text { decrease } \\
\text { in LWC }\end{array}$ & -4 & -236 & 2 & 4.5 & -1 & -5.2 & -1.5 & -0.23 & -2 & 0.23 \\
\hline & $1 \mathrm{std}$ dev & & 70 & & 1.8 & & 1.1 & & 0.11 & & 0.07 \\
\hline \multirow{2}{*}{0.75} & $\begin{array}{c}15 \% \\
\text { increase } \\
\text { in LWC }\end{array}$ & 1 & 70 & $<1$ & $<1.8$ & 4 & 4.4 & 1.5 & 0.17 & 1.5 & 0.11 \\
\hline & $\begin{array}{c}15 \% \\
\text { decrease } \\
\text { in LWC }\end{array}$ & -2.5 & -175 & 2 & 3.6 & 2 & 2.2 & -4 & -0.44 & -4 & -0.28 \\
\hline
\end{tabular}

The data in this table show changes in ice feature values determined from the contour plots that are of the same order of magnitude as observed in the earlier sensitivity test, but somewhat smaller in value. The mass change values for the cold temperature $\eta_{0}=0.75$, appears to be too low. One would expect a greater change in mass at $\eta_{0}=0.75$, than at the $\eta_{0}=0.39$. This discrepancy is probably due to an artifact of the interpolation algorithm, since some test points were removed from the database at the cold condition during the quality control process. These points were located on the contour plots above and to the right of the nominal condition during the quality control process.

Inspection of figures 7 through 16, suggests that removal of these data points has also affected each of the other parameters at the cold temperature. Thus the artifacts introduced by the interpolation routine 
have affected the absolute values of the data in table 6 . The variation of the horn angles, were probably most affected as seen by the two positive values for an increase in $L W C$ and a decrease in $L W C$.

Generally speaking the overall trends in table 6 were similar to those observed in the previous sensitivity test:

- An increase in $L W C$ resulted in a mass increase, and a decrease in $L W C$ resulted in a decrease in mass.

- An increase in $L W C$ resulted in a decrease in upper horn angle (as computed by THICK), since the horn would be expected to rotate aft on the upper surface, and a decrease in $L W C$ resulted in an increase in upper horn angle.

- An increase in $L W C$ resulted in an increase in lower horn angle, and a decrease in $L W C$ resulted in a decrease in lower horn angle.

- An increase in $L W C$ led to an increase in horn thickness and a decrease in $L W C$ resulted in a decrease in horn thickness.

Table 7 lists the value of ice feature change associated with a 15 percent variation in $M V D$, which would correspond to a change of $4.3 \mu \mathrm{m}$. The values in the table were obtained from the contour plots in figures 7 through 16, by moving vertically up (increase) or down (decrease) with respect to nominal condition, and then determining the value of the contour line which intersected the 15 percent variation line. In cases where the 15 percent box did not intersect a contour line, judgment was used to estimate what the intersecting contour line would have been.

TABLE 7.-CONTOUR PLOT ICE FEATURE CHANGES FOR 15 PERCENT CHANGE IN MVD

\begin{tabular}{|c|c|c|c|c|c|c|c|c|c|c|c|}
\hline \multirow{2}{*}{$\eta_{0}$} & \multirow{2}{*}{ Change } & \multicolumn{2}{|c|}{$\begin{array}{l}\text { Ice Shape } \\
\text { Mass }\end{array}$} & \multicolumn{2}{|c|}{$\begin{array}{l}\text { Upper Horn } \\
\text { Angle }\end{array}$} & \multicolumn{2}{|c|}{$\begin{array}{l}\text { Lower Horn } \\
\text { Angle }\end{array}$} & \multicolumn{2}{|c|}{$\begin{array}{l}\text { Upper Horn } \\
\text { Thickness }\end{array}$} & \multicolumn{2}{|c|}{$\begin{array}{l}\text { Lower Horn } \\
\text { Thickness }\end{array}$} \\
\hline & & $\begin{array}{l}\text { std } \\
\text { dev }\end{array}$ & gm & $\begin{array}{l}\text { std } \\
\text { dev }\end{array}$ & deg & $\begin{array}{l}\text { std } \\
\text { dev }\end{array}$ & deg & $\begin{array}{l}\text { std } \\
\text { dev }\end{array}$ & inch & $\begin{array}{l}\text { std } \\
\text { dev }\end{array}$ & inch \\
\hline & $1 \mathrm{std}$ dev & & 59 & & 2.25 & & 5.2 & & 0.15 & & 0.115 \\
\hline \multirow{2}{*}{0.39} & $\begin{array}{c}15 \% \\
\text { increase } \\
\text { in MVD }\end{array}$ & 1 & 59 & -1 & -2.3 & 1 & 5.2 & 0.5 & 0.08 & 0.7 & 0.08 \\
\hline & $\begin{array}{c}15 \% \\
\text { decrease } \\
\text { in MVD }\end{array}$ & -3 & -177 & 2.5 & 5.6 & -1.5 & -7.8 & -1.5 & -0.23 & -0.7 & -0.08 \\
\hline & 1 std dev & & $\overline{70}$ & & 1.8 & & 1.1 & & 0.11 & & 0.07 \\
\hline \multirow{2}{*}{0.75} & $\begin{array}{c}15 \% \\
\text { increase } \\
\text { in MVD }\end{array}$ & 1 & 70 & 1 & 1.8 & 4 & 4.4 & -1 & -0.11 & 1 & 0.1 \\
\hline & $\begin{array}{c}15 \% \\
\text { decrease } \\
\text { in MVD }\end{array}$ & -4 & -280 & 1 & 1.8 & 1 & 1.1 & -4 & -0.44 & -4 & -0.44 \\
\hline
\end{tabular}

The data in this table show changes in ice feature values determined from the contour plots that are of the same order of magnitude as those observed in the earlier sensitivity test, however they have a smaller magnitude. Since the earlier sensitivity test considered $M V D$ changes of $\pm 50 \mu \mathrm{m}$, this would be expected.

Inspection of figures 7 through 16, suggests that removal of data points from the database during the quality control process appears to have affected the ice feature change parameters determined from the contour plots at the cold temperature. Artifacts due to the interpolation process are evident in the upper and lower horn angle change at the cold temperature, as they both have positive values. 
Generally speaking the overall trends in table 7 were similar to those observed in the previous sensitivity test:

- An increase in $M V D$ resulted in a mass increase, and a decrease in $M V D$ resulted in a decrease in mass.

- An increase in $M V D$ resulted in a decrease in upper horn angle (as computed by THICK), since the horn would be expected to rotate aft on the upper surface, and a decrease in $M V D$ resulted in an increase in upper horn angle.

- An increase in $M V D$ resulted in an increase in lower horn angle, and a decrease in $M V D$ resulted in a decrease in lower horn angle.

\section{Conclusions}

The results from a second ice shape sensitivity test have been presented. This second sensitivity test used a different approach to study the effect of smaller spray parameter variations and their resultant effect on ice shape features. A matrix of discrete spray conditions was used to develop contour maps of the change in ice shape features, due to spray parameter variations about a nominal spray condition of $\left(P_{\text {air nom }}=25 \mathrm{psi}, \Delta P_{\text {nom }}=120 \mathrm{psi}, L W C_{\text {nom }}=0.827 \mathrm{~g} / \mathrm{m}^{3}, M V D=28.7 \mu \mathrm{m}\right)$. While the alternate method did facilitate the quantification of trends and ice shape feature changes, there was a higher level of uncertainty associated with the results, than with the results from the first icing sensitivity test. This higher degree of uncertainty was attributed to experimental test procedure issues (2004 heater mat and ice mass measurement), which have been previously discussed in this report. The trends associated with ice feature changes due to spray parameter variations in this test were similar to what was observed in the previous ice sensitivity test.

Some specific conclusions and recommendations are listed below:

- It is believed that the concept of using contour plots to quantify ice shape feature change has merit, with some modifications to the implementation of the method.

$\circ$ Spray conditions could be selected in the way of the first sensitivity test by selecting $L W C$ and $M V D$ values allowing independent variation of $L W C$ and $M V D$.

$\circ$ The $\left(P_{\text {air }}, \Delta P\right)$ spray condition could be defined such that $P_{\text {air }}$ is selected to correspond to one of the fixed $P_{\text {air }}$ conditions (e.g., $P_{\text {air }}=10$ psi, 15 psi, 20 psi, etc.) for which a calibration curve has been generated as a function of the water pressure parameter $\Delta P$. The calibration curve for that $P_{\text {air }}$ could then be used to define the $\Delta P$ necessary to provide the desired $L W C$. It is believed this approach could reduce experimental uncertainties.

- Quantitative methods were applied to the evaluation of ice shape features in this study. It is believed that the quantitative methods are required to discern subtle changes in ice shape features, and facilitate comparisons over a range of different conditions. The THICK analysis program proved to be a valuable analysis tool, but there were some limitations identified regarding it's use in cold temperatures due to the formation of large ice feathers aft of the main ice shape. The presence of these ice feathers tended to complicate the analysis, introducing more variability into the computed horn angles and horn thicknesses. This issue needs to be considered when using THICK at cold temperatures where the freezing fraction is relatively high.

- Experimental test method issues introduced uncertainty into the ice shape feature measurements. A small heater gap on the lower surface of the airfoil induced noticeable lower surface ice shape features at larger $M V D$ at the cold temperature. The subsequent removal of these conditions from the database, affected the ability to discern and quantify ice feature changes from contour plots. Improvements in the experimental method are warranted for future testing. 
Based on what has been learned from this study, there are a number of recommendations regarding future work in this area.

- Future investigations using this approach should consider implementing the modifications suggested above, as well as the following improvements to the experimental process:

$\circ \quad$ Utilize single piece heater assemblies to minimize any aerodynamic effects.

$\circ$ More closely monitor the area of the heater mat over which ice is being removed during the test.

- Consider a smaller test matrix with at least one repeat per test condition.

- Develop some preliminary estimates of the needed resolution in ice feature change measurements, based on iced aerodynamic performance factors. It is envisioned this might be accomplished by reviewing the large body of work that exists on iced aerodynamic performance, and possibly complimented by conducting appropriate CFD investigations. These estimates could then be used to help define the desired level of parameter variations for future sensitivity tests.

- It is recognized that the results of this study have limitations associated with only evaluating one airfoil. Different airfoil characteristics (geometry, chord, etc.) could exhibit differences relative to what has been reported here. Therefore, it would be desirable to conduct tests on other airfoil geometries.

\section{References}

1. Bond, T., Miller, D., and Potapczuk, M., "Overview of SLD Engineering Tools Development," AIAA-2003-0386.

2. Miller, D., Potapczuk, M., Bond, and T., "Update on SLD Engineering Tools Development," SAE2003-01-2127.

3. Miller, D., Potapczuk, M., Langhals, and T., "Preliminary Investigation of Ice Shape Sensitivity to Parameter Variations," AIAA-2005-0073, 43rd AIAA Aerospace Sciences Meeting and Exhibit, January 10-13, 2005.

4. Wright, W. and Rutkowski, A., "Validation Report for LEWICE 2.0," NASA/CR-208690, January 1999. 


\begin{tabular}{|c|c|c|c|}
\hline \multicolumn{3}{|c|}{ REPORT DOCUMENTATION PAGE } & $\begin{array}{l}\text { Form Approved } \\
\text { OMB No. 0704-0188 }\end{array}$ \\
\hline \multicolumn{4}{|c|}{ 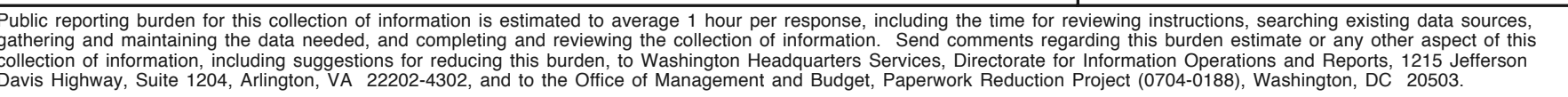 } \\
\hline 1. AGENCY USE ONLY (Leave blank) & $\begin{array}{r}\text { 2. REPORT DATE } \\
\text { March } 2006\end{array}$ & 3. 1 & $\begin{array}{l}\text { ND DATES COVERED } \\
\text { echnical Memorandum }\end{array}$ \\
\hline \multicolumn{3}{|c|}{$\begin{array}{l}\text { 4. TITLE AND SUBTITLE } \\
\text { Additional Investigations of Ice Shape Sensitivity to Parameter Variations }\end{array}$} & 5. FUNDING NUMBERS \\
\hline \multicolumn{3}{|c|}{ Dean R. Miller, Mark G. Potapczuk, and Tammy J. Langhals } & WBS-22-077-41-02 \\
\hline \multicolumn{3}{|c|}{$\begin{array}{l}\text { National Aeronautics and Space Administration } \\
\text { John H. Glenn Research Center at Lewis Field } \\
\text { Cleveland, Ohio } 44135-3191\end{array}$} & $\begin{array}{l}\text { 8. PERFORMING ORGANIZATION } \\
\text { REPORT NUMBER } \\
\text { E-15474 }\end{array}$ \\
\hline \multicolumn{2}{|c|}{$\begin{array}{l}\text { National Aeronautics and Space Administration } \\
\text { Washington, DC 20546-0001 }\end{array}$} & & $\begin{array}{l}\text { 10. SPONSORING/MONITORING } \\
\text { AGENCY REPORT NUMBER } \\
\text { NASA TM-2006-214227 } \\
\text { AIAA-2006-0469 }\end{array}$ \\
\hline \multicolumn{4}{|l|}{ 11. SUPPLEMENTARY NOTES } \\
\hline \multicolumn{4}{|c|}{$\begin{array}{l}\text { Prepared for the 44th Aerospace Sciences Meeting and Exhibit sponsored by the American Institute of Aeronautics and } \\
\text { Astronautics, Reno, Nevada, January 9-12, 2006. Dean R. Miller and Mark G. Potapczuk, NASA Glenn Research Center; } \\
\text { and Tammy J. Langhals, QSS Group, Inc., } 21000 \text { Brookpark, Cleveland, Ohio 44135. Responsible person, Dean Miller, } \\
\text { organization code RTI, 216-433-5349. }\end{array}$} \\
\hline
\end{tabular}

\begin{tabular}{|l|l|}
\hline 12a. DISTRIBUTION/AVAILABILITY STATEMENT & 12b. DISTRIBUTION CODE
\end{tabular}

Unclassified - Unlimited

Subject Category: 03

Available electronically at http://gltrs.grc.nasa.gov

This publication is available from the NASA Center for AeroSpace Information, 301-621-0390.

13. ABSTRACT (Maximum 200 words)

A second parameter sensitivity study was conducted at the NASA Glenn Research Center's Icing Research Tunnel (IRT) using a 36 in. chord $(0.91 \mathrm{~m})$ NACA-0012 airfoil. The objective of this work was to further investigate the feasibility of using ice shape feature changes to define requirements for the simulation and measurement of SLD and appendix C icing conditions. A previous study concluded that it was feasible to use changes in ice shape features (e.g., ice horn angle, ice horn thickness, and ice shape mass) to detect relatively small variations in icing spray condition parameters ( $L W C, M V D$, and temperature). The subject of this current investigation extends the scope of this previous work, by also examining the effect of icing tunnel spray-bar parameter variations (water pressure, air pressure) on ice shape feature changes. The approach was to vary spray-bar water pressure and air pressure, and then evaluate the effects of these parameter changes on the resulting ice shapes. This paper will provide a description of the experimental method, present selected experimental results, and conclude with an evaluation of these results.

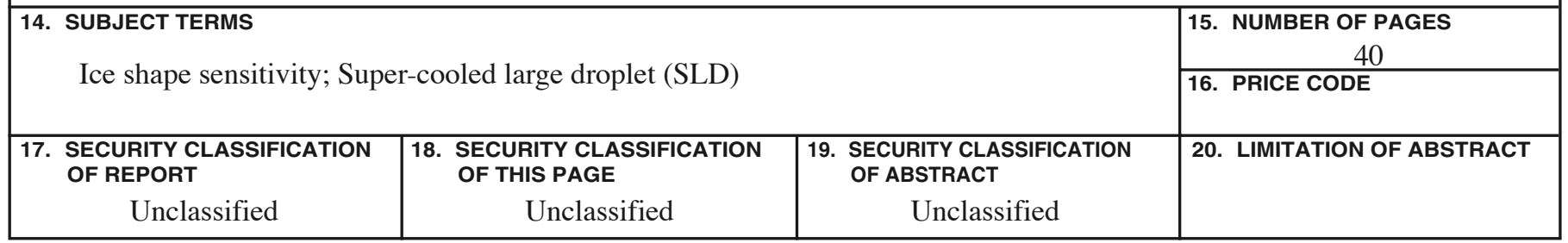



